\title{
Genes Related to Mitochondrial Functions, Protein Degradation, and Chromatin Folding Are Differentially Expressed in Lymphomonocytes of Rett Syndrome Patients
}

\author{
Alessandra Pecorelli, ${ }^{1,2}$ Guido Leoni, ${ }^{3}$ Franco Cervellati, ${ }^{4}$ Raffaella Canali, ${ }^{3}$ \\ Cinzia Signorini, ${ }^{1}$ Silvia Leoncini, ${ }^{1,2}$ Alessio Cortelazzo, ${ }^{2,5}$ Claudio De Felice, ${ }^{6}$ \\ Lucia Ciccoli, ${ }^{1}$ Joussef Hayek, ${ }^{2}$ and Giuseppe Valacchi, ${ }^{4,7}$ \\ ${ }^{1}$ Department of Molecular and Developmental Medicine, University of Siena, 53100 Siena, Italy \\ ${ }^{2}$ Child Neuropsychiatry Unit, University Hospital, Azienda Ospedaliera Universitaria Senese, 53100 Siena, Italy \\ ${ }^{3}$ National Research Institute on Food and Nutrition (INRAN), 00178 Rome, Italy \\ ${ }^{4}$ Department of Life Science and Biotechnologies, University of Ferrara, 44121 Ferrara, Italy \\ ${ }^{5}$ Department of Medical Biotechnologies, University of Siena, 53100 Siena, Italy \\ ${ }^{6}$ Neonatal Intensive Care Unit, University Hospital, Azienda Ospedaliera Universitaria Senese, 53100 Siena, Italy \\ ${ }^{7}$ Department of Food and Nutrition, Kyung Hee University, Seoul 130-701, Republic of Korea
}

Correspondence should be addressed to Giuseppe Valacchi; giuseppe.valacchi@unife.it

Received 11 October 2013; Accepted 7 November 2013

Academic Editor: Paul Ashwood

Copyright (C) 2013 Alessandra Pecorelli et al. This is an open access article distributed under the Creative Commons Attribution License, which permits unrestricted use, distribution, and reproduction in any medium, provided the original work is properly cited.

\begin{abstract}
Rett syndrome (RTT) is mainly caused by mutations in the X-linked methyl-CpG binding protein $(\mathrm{MeCP} 2)$ gene. By binding to methylated promoters on $\mathrm{CpG}$ islands, $\mathrm{MeCP} 2$ protein is able to modulate several genes and important cellular pathways. Therefore, mutations in $\mathrm{MeCP} 2$ can seriously affect the cellular phenotype. Today, the pathways that MeCP2 mutations are able to affect in RTT are not clear yet. The aim of our study was to investigate the gene expression profiles in peripheral blood lymphomonocytes (PBMC) isolated from RTT patients to try to evidence new genes and new pathways that are involved in RTT pathophysiology. LIMMA (Linear Models for MicroArray) and SAM (Significance Analysis of Microarrays) analyses on microarray data from 12 RTT patients and 7 control subjects identified 482 genes modulated in RTT, of which 430 were upregulated and 52 were downregulated. Functional clustering of a total of 146 genes in RTT identified key biological pathways related to mitochondrial function and organization, cellular ubiquitination and proteosome degradation, RNA processing, and chromatin folding. Our microarray data reveal an overexpression of genes involved in ATP synthesis suggesting altered energy requirement that parallels with increased activities of protein degradation. In conclusion, these findings suggest that mitochondrial-ATP-proteasome functions are likely to be involved in RTT clinical features.
\end{abstract}

\section{Introduction}

Rett syndrome (RTT) is a rare form of autism spectrum disorder (ASD), which mostly affects girls with worldwide prevalence rate ranges from $1: 10,000$ to $1: 20,000$ live births [1-5]. RTT is a clinically defined condition with a large spectrum of phenotypes associated with a wide genotypic variability $[6,7]$. Classic or typical RTT, the most common form of the condition, is caused in about $90-95 \%$ of cases by de novo mutations in the $\mathrm{MeCP} 2$, a gene mapped on chromosome $\mathrm{X}$ and encoding methyl-CpG binding protein $2[7,8]$. The clinical picture of classical form progresses through 4 stages and is characterized by normal development for the first 6 to 18 months, followed by loss of purposeful hand movements, failure of speech development, autistic-like behavior, slowed brain and head growth, and mental retardation [9].

To date, it is not known how $\mathrm{MeCP} 2$ mutations lead to RTT phenotypes; therefore the identification of the pathways 
that are affected by $M e C P 2$ functions could bring new insight in the RTT pathogenetic mechanisms. MeCP2 was originally thought to function as a transcription repressor by binding to methylated $\mathrm{CpG}$ dinucleotides, but recent studies have individuated more functions related to MeCP2 [10, 11]. In fact $\mathrm{MeCP} 2$ is now considered a multifunctional protein, since it is implicated not only in genome transcriptional silencing, but also in transcriptional activation, by regulating chromatin and nuclear architecture [11]; therefore, its malfunction or mutation can lead to severe cellular function alterations.

Hence, it is very difficult to understand the link between $M e C P 2$ mutation and the clinical feature present in RTT. One of the most common approaches used to better understand the molecular pathways involved in genetic disorders has been the determination of gene expression profiling, since it provides the opportunity to evaluate possible transcriptome alterations at both gene and gene-network levels. This approach should not be considered an end point but a magnifying lent where new aspects involved in the diseases can be discovered and then studied.

So far, only a handful of studies have investigated the gene expression profiles of RTT children in tissues, that is, postmortem brain samples [12], or in cells, such as clones of fibroblasts isolated from skin biopsies $[13,14]$ and immortalized lymphoblastoid cell lines [14-16]. Moreover, several studies have performed microarray gene expression analysis using in vitro cellular models representing MeCP2 deficiency induced by siRNAs [17] or cells and tissues from RTT mouse models [18], but to our knowledge there are no data on microarray analysis from "ex vivo" fresh samples. For this reason, the aim of this study was to evaluate the gene expression patterns in PBMC isolated from RTT patients. This approach lets us bypass some of the limitations/variables of the previous gene arrays studies on RTT, such as the use of postmortem samples, gene-modified cells and murine tissues that do not always reflect all features of the human disease. In fact, studying ex vivo samples, such as PBMC, provides some advantage that can be summarized by the fact PBMC are the only readily available cells in humans; various studies showed disease-characteristic gene expression patterns in PBMC that can be easily obtained.

Our results identified a clear difference in gene expression profile between control and RTT patients, with almost 500 genes being deregulated, suggesting several new pathways involved in this disorder.

\section{Subjects and Methods}

2.1. Subjects Population. The study included 12 female patients with clinical diagnosis of typical RTT (mean age: $10.9 \pm 4.9$ years, range: $6-22$ ) with demonstrated MeCP2 gene mutation and 7 sex- and age-matched healthy controls (mean age: $15.1 \pm 9.03$ years, range: $4-32$ ). RTT diagnosis and inclusion/exclusion criteria were based on the recently revised RTT nomenclature consensus [4]. All the patients were consecutively admitted to the Rett Syndrome National Reference Centre of the University Hospital of the Azienda Ospedaliera Universitaria Senese (AOUS). Table 1 presents
TABLE 1: Demographic and genetic data for RTT patients enrolled in study.

\begin{tabular}{cccccc}
\hline No. Age & Stage & Mutation type & $\begin{array}{c}\text { Nucleotide } \\
\text { change }\end{array}$ & $\begin{array}{c}\text { Amino acid } \\
\text { change }\end{array}$ \\
\hline$\# 1$ & 7 & 3 & ETMs & & \\
$\# 2$ & 10 & 3 & missense & c.403A $>\mathrm{G}$ & p.K135E \\
$\# 3$ & 9 & 4 & missense & c.403A $>\mathrm{G}$ & p.K135E \\
$\# 4$ & 9 & 4 & missense & c.455C $>\mathrm{G}$ & p.P152R \\
$\# 5$ & 12 & 3 & missense & c.473C $>\mathrm{T}$ & p.T158M \\
$\# 6$ & 19 & 3 & nonsense & c.763C $>\mathrm{T}$ & p.R255X \\
& & & frameshift & & \\
$\# 7$ & 22 & 3 & insertion or & c.806_807delG & p.G269fs \\
& & & deletion & & \\
$\# 8$ & 7 & 4 & nonsense & c.808C $>\mathrm{T}$ & p.R270X \\
$\# 9$ & 7 & 3 & nonsense & c.808C $>\mathrm{T}$ & p.R270X \\
$\# 10$ & 12 & 4 & nonsense & c. $880 \mathrm{C}>\mathrm{T}$ & p.R294X \\
$\# 11$ & 6 & 3 & nonsense & c.880C $>\mathrm{T}$ & p.R294X \\
$\# 12$ & 11 & 3 & missense & c.916C $>\mathrm{T}$ & p.R306C \\
\hline
\end{tabular}

ETMs: early truncating mutations.

the demographic and genetic characteristics of the enrolled patients subjected to microarray analysis. Blood sampling in the control group was carried out during routine health checks, sports, or blood donations, while blood sample in patients were obtained during the periodic clinical checks. The study was conducted with the approval of the Institutional Review Board and all informed consents were obtained from either the parents or the legal tutors of the enrolled patients.

2.2. Blood Specimen Collection, Peripheral Blood Lymphomonocytes Isolation, and RNA Extraction. Blood was collected in heparinized tubes and all manipulations were carried out within 30 minutes after sample collection. PBMC were separated from whole blood by density gradient centrifugation using Ficoll-Paque PLUS (GE Healthcare Europe $\mathrm{GmbH}$, Milan, Italy). After PBMC isolation, total RNA was extracted from cells using RNeasy mini kit (Qiagen, Hilden, Germany), according to the manufacturer's instructions. The total nucleic acid concentration and purity were estimated using a NanoDrop spectrophotometer (NanoDrop Technologies, Wilmington, DE). Quality of RNA was checked on Agilent bioanalyzer (Agilent Technologies, Santa Clara, CA). The isolated RNA samples were stored at $-80^{\circ} \mathrm{C}$ until the analysis.

2.3. Microarray Processing. For the microarray processing, RNA was amplified and labeled using the Affymetrix WholeTranscript (WT) Sense Target Labeling Protocol. Affymetrix GeneChip Human Gene 1.0 ST arrays were hybridized with labeled sense DNA, washed, stained, and scanned according to the protocol described in WT Sense Target Labeling Assay Manual.

Briefly, 100 ng of total RNA was reverse transcribed into double-stranded cDNA with random hexamers tagged with 
a T7 promoter sequence. The double-stranded cDNA was subsequently used as a template and amplified by T7 RNA polymerase, producing many copies of antisense cRNA. In the second cycle of cDNA synthesis, random hexamers were used to prime reverse transcription of the cRNA from the first cycle to produce single-stranded DNA in the sense orientation. dUTP was incorporated in the DNA during the secondcycle, first-strand reverse transcription reaction. This singlestranded DNA sample was then treated with a combination of uracil DNA glycosylase (UDG) and apurinic/apyrimidinic endonuclease 1 (APE 1) that specifically recognized the unnatural dUTP residues and broke the DNA strand. DNA was labeled by terminal deoxynucleotidyl transferase (TdT) with the Affymetrix proprietary DNA Labeling Reagent that is covalently linked to biotin. $5 \mu \mathrm{g}$ of labeled cDNA was hybridized to the Human Gene $1.0 \mathrm{ST}$ Array at $45^{\circ} \mathrm{C}$ for 17 hours. The arrays were washed and stained in Affymetrix Fluidics Station 450 and scanned using the Affymetrix GeneChip Scanner 3000.

2.4. Microarray Data Analysis. The microarray experiments were analyzed with the oneChannelGUI package available in $\mathrm{R}$ software. The signal intensities from each chip were preliminarily normalized with RMA method and filtered by IQR filter choosing as threshold a value of 0.25 . This specific filter removes the probesets that do not present changes in their expression across the analyzed microarray. The threshold of 0.25 is an intermediate value that retains the probesets that show significative changes of their signal at least in the $25 \%$ of analyzed microarray. The microarray data were analyzed by SAM and LIMMA analyses. SAM approach uses permutation based statistics and is a valid method to analyze data that may not follow a normal distribution, outperforming other techniques (e.g., ANOVA and classical $t$-test), which assume equal variance and/or independence of genes. LIMMA fit each gene expression to a linear regression model testing the significativity of the distance from the model with a $t$-test robust against nonnormality and inequality of variances. In order to characterize the biological processes enriched in the list of modulated genes, a statistical analysis of overrepresented Gene Ontology (GO) terms (BP level 5) was performed with DAVID (Database for Annotation, Visualization, and Integrated Discovery) web server (DAVID Bioinformatics Resources) [19]. Only the GO terms enriched with a $P$ value $<0.05$ corrected with the Benjamini and Hochberg method [20] were selected and hierarchically clusterized (Ward's method) according to their "semantic" similarity estimated with the GOSIM R package with default parameters. After clusterization the best number of clusters was identified according to the analysis of the silhouette scores and the medoid term in each cluster was selected as the representative member of the cluster. Each cluster represents a group of biological processes with similar e/o related functions.

2.5. Validation of Microarray Data by RT-qPCR (Reverse Transcription Quantitative Real-Time PCR). For confirmation of Affymetrix expression microarray results, RT-qPCR analysis was performed as previously described [21]. For validation, six of the differentially expressed genes, 3 upregulatedGSTO1, PSMB10 and COX8A-and 3 downregulatedHIST1H1B, MMP9 and ARHGAP11B-by microarray, were chosen. Validation was done in a randomly selected subset of the original samples (submitted for microarray analysis) that included 3 healthy controls and 3 RTT patients. Primer pairs were obtained from the Real-time PCR GenBank Primer to hybridise unique regions of the appropriate gene sequence: GSTO1 (Fw: 5'-AGA GTT GTT TTC TAA GGT TCT GAC T- $3^{\prime}$ ) and (RW: $5^{\prime}$-ACT TCA TTG CTT CCA GCC GT$3^{\prime}$ ), product length $116 \mathrm{bp}$; PSMB10 (Fw: $5^{\prime}$-ACA GAC GTG AAG CCT AGC AG-3') and (Rw: $5^{\prime}$-ACC GAA TCG TTA GTG GCT CG-3'), product length $294 \mathrm{bp}$; COX8A (Fw: $5^{\prime}$ GCC AAG ATC CAT TCG TTG CC- $3^{\prime}$ ) and (RW: $5^{\prime}$-TCT GGC CTC CTG TAG GTC TC-3'), product length 137 bp; HIST1H1B (Fw: $5^{\prime}$-CCC GGC TAA GAA GAA GGC AA$3^{\prime}$ ) and (RW: $5^{\prime}$-ACA GCC TTG GTG ATC AGC TC- $3^{\prime}$ ), product length $99 \mathrm{bp}$; MMP9 (Fw: $5^{\prime}$-GTC CGT GAG GGT GTT GAG TG-3') and (RW: $5^{\prime}$-ACT GCT CAA AGC CTC CAC AA- $3^{\prime}$ ), product length $145 \mathrm{bp} ; A R H G A P 11 B\left(\mathrm{Fw}: 5^{\prime}\right.$ AAC TGC CAG AGC CCA TTC TC- $3^{\prime}$ ) and (RW: $5^{\prime}-\mathrm{GTC}$ TGG TAC ACG CCC TTC TT- $3^{\prime}$ ), product length $295 \mathrm{bp}$. All reactions were run in triplicate. GAPDH (FW: $5^{\prime}$-TGA CGC TGG GGC TGG CAT TG-3' and RW: $5^{\prime}$-GGC TGG TGG TCC AGG GGT CT-3', 134 pb) was used in our experiments as internal standard. As previously described, samples were compared using the relative cycle threshold (CT) method (Livak and Schmittgen 2001). After normalization to more stable mRNA GAPDH, the fold increase or decrease was determined with respect to control, using the formula $2^{-\Delta \Delta C T}$, where $\Delta \mathrm{CT}$ is (gene of interest $\mathrm{CT})-($ reference gene $\mathrm{CT}$ ) and $\Delta \Delta \mathrm{CT}$ is ( $\Delta \mathrm{CT}$ experimental $)-(\Delta \mathrm{CT}$ control $)$. Results are the means \pm SEM of three independent experiments, each analysed in triplicate. ${ }^{*} P<0.001$ versus control (one-way ANOVA followed by Bonferroni's posttest).

\section{Results and Discussion}

3.1. Differentially Regulated Genes in RTT Patients. Given that RTT results from dysfunction of the transcriptional modulator MeCP2, several strategies have been developed to identify its target genes in order to gain insights into the disease pathogenesis [12-18]. In our study, to identify gene expression changes associated with and potentially related to MeCP2 mutations and to delineate alterations of pathways associated with the disease, we evaluated and compared transcriptomic profiles in PBMC from RTT patients and control subjects.

This work showed for the first time, to our knowledge, altered expression of a large set of genes that may help elucidating and explaining the link between MeCP2 and some of the molecular and cellular aspects observed in RTT patients. In our previous studies on RTT we were able to show increased levels of oxidative stress (OS) markers, such as isoprostanes (IsoPs) and 4-hydroxynonenal protein adducts (4-HNE PAs) [22, 23], and increased ubiquitination and degradation of oxidatively modified proteins [24], but how 


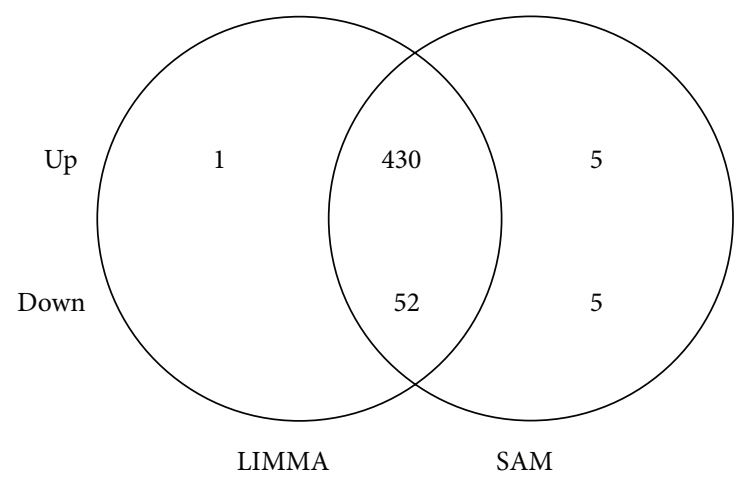

FIGURE 1: Comparison of two distinct approaches for screening of differentially expressed genes in RTT PBMC. Venn diagram representing numbers of common and exclusively up- and downregulated genes for LIMMA (left) and SAM (right) analyses (FC \pm 1 ; adj. $P$ value $\leq 0.05)$. The 11 genes indicated by only one method were excluded by further analysis.

$\mathrm{MeCP} 2$ mutation is able to affect cellular redox balance and proteins turn over still needs to be defined.

Using the SAM and LIMMA methods, we have defined a set of genes differentially expressed in RTT patients with respect to controls (healthy subjects) and a significant overlap was found by comparing results from two approaches. A cut-off level based on a minimum of 1 -fold change in expression resulted in a list of 482 common deregulated genes, while 10 genes were suggested only by SAM and only 1 gene was indicated by LIMMA. Among the shared genes, 430 showed significant upregulation, while 52 were downregulated in RTT compared to controls (Figure 1 and Supplemental Tables 1 and 2). The 11 genes indicated by only one method were excluded for further analysis. Genes with the strongest changes in expression, both upregulated (FC $\geq$ 2 ) and downregulated ( $\mathrm{FC} \leq-1.2)$, are listed in Tables 2 and 3 , respectively. The complete list of differentially expressed genes, both upregulated and downregulated $(\mathrm{FC} \pm 1)$, is shown in Supplemental Tables 1 and 2.

It is evident from this first set of data that mutations in $M e C P 2$ influence more the genes upregulation with respect to the downregulation. This is in part in line with the first functions that have been attributed to $\mathrm{MeCP} 2$, such as a gene expression repressor $[10,11]$. In addition, it is worth it to underline that both screening approaches used in this study (LIMMA and SAM) almost overlap between them making the results more reliable.

Next, using the DAVID databases, we performed the functional annotation of the significant genes and identification of the biochemical pathways in which they are involved. A comparison of the differentially regulated mRNA transcripts in RTT PBMC compared to control group shows significant changes in cellular pathways. In particular, we identify 10 major clusters corresponding to 62 biological processes enriched by 146 genes (Table 4). These clusters highlight key biological pathways related to mitochondrial function and organization (i.e., mitochondrial ATP synthesis coupled to electron transport, inner mitochondrial membrane organization such as: ATP5A1, COX6C, ETFA, UQCRQ, TIMM10, and TSPO), cellular protein metabolic process (i.e., regulation of protein ubiquitination, regulation of ubiquitinprotein ligase activity, and proteasomal ubiquitin-dependent protein catabolic process such as PSMA2, PSMD6, UBE2E3, and $U F C$ ), RNA processing (i.e., nuclear mRNA splicing and spliceosome assembly and RNA elongation from RNA polymerase II promoter such as RPL15), DNA organization in chromatin, and cellular macromolecular complex assembly (i.e., nucleosome assembly, DNA packaging, and protein complex biogenesis such as HIST1H4L, H2AFZ, TOP2A, and HMGB2).

3.2. Mitochondrial Related Genes in RTT Patients. Among these clusters, the most significantly regulated transcripts include those encoding several subunits of mitochondrial respiratory chain complexes and thus linked directly to mitochondrial ATP production and, indirectly, to potential reactive oxygen species (ROS) generation. In particular, NDUFA1, NDUFAB1, NDUFA2, and NDUFB6, all components of mitochondrial complex I (NADH: ubiquinone oxidoreductase), showed the greater changes with a FC of more than 2. Moreover, other subunits of complex I (NDUFV2, NDUFS4, NDUFA9, NDUFS6, NDUFB10, NDUFB4, NDUFC2, NDUFB2, NDUFS5, NDUFC1, NDUFB9, and NDUFA8) were clearly upregulated in RTT group.

Complex I plays a vital role in cellular ATP production, the primary source of energy for many crucial processes in living cells. It removes electrons from $\mathrm{NADH}$ and passes them by a series of different protein coupled redox centers to the electron acceptor ubiquinone. Because complex I is central to energy production in the cell, it is reported that its malfunction results in a wide range of neuromuscular diseases [25]. Some of them are due to mutations in the mitochondrial genome, but others, which result from a decrease in the activity of complex I or an increase in the production of ROS, are not well understood. The production of ROS by complex I is linked to Parkinson's disease and to ageing $[26,27]$ and this is in line with RTT since it is now well documented as an increased OS condition in this pathology $[22,23]$.

Another gene involved in complex I function is NDUFV2 that was also clearly upregulated in our study. Mutations in this gene are implicated in Parkinson's disease, bipolar disorder, and schizophrenia and have been found in one case of early onset hypertrophic cardiomyopathy and encephalopathy; also it has been shown for NDUFA2, a subunit of the hydrophobic protein fraction of the complex I. Mutations in this gene are associated with Leigh syndrome, an early onset progressive neurodegenerative disorder. Of note is NDUFAB1, which is a carrier of the growing fatty acid chain in fatty acid biosynthesis in mitochondria and alteration in fatty acid levels has been noted in ASD [28, 29].

Not only complex I subunits were upregulated in RTT, but also we have detected an upregulation of genes involved in all the five complexes of the electron transport chain. In fact, also $S D H B$ (succinate dehydrogenase complex, subunit 
TABLE 2: Genes upregulated in RTT patients by LIMMA and SAM analyses.

\begin{tabular}{|c|c|c|c|c|c|}
\hline $\begin{array}{l}\text { NCBI reference } \\
\text { sequence }\end{array}$ & Gene symbol & Gene name & Molecular function & Biological process & Fold change \\
\hline NM_004541.3 & NDUFA1 & $\begin{array}{l}\text { NADH dehydrogenase } \\
\text { (ubiquinone) } 1 \text { alpha } \\
\text { subcomplex, } 1,7.5 \mathrm{kDa}\end{array}$ & $\begin{array}{l}\text { NADH dehydrogenase } \\
\text { (ubiquinone) activity }\end{array}$ & $\begin{array}{l}\text { Mitochondrial electron transport, } \\
\text { NADH to ubiquinone }\end{array}$ & 3.1 \\
\hline NM_006498.2 & LGALS2 & $\begin{array}{l}\text { Lectin, } \\
\text { galactoside-binding, } \\
\text { soluble, } 2\end{array}$ & Carbohydrate binding & - & 2.8 \\
\hline NM_014302.3 & SEC61G & Sec61 gamma subunit & $\begin{array}{l}\text { Protein transporter } \\
\text { activity }\end{array}$ & $\begin{array}{l}\text { Protein targeting to ER; antigen } \\
\text { processing and presentation of } \\
\text { exogenous peptide antigen via } \\
\text { MHC class I }\end{array}$ & 2.8 \\
\hline NM_001040437.1 & C6orf48 & $\begin{array}{l}\text { Chromosome } 6 \text { open } \\
\text { reading frame } 48\end{array}$ & - & - & 2.7 \\
\hline NM_001098577.2 & RPL31 & Ribosomal protein L31 & $\begin{array}{l}\text { RNA binding; structural } \\
\text { constituent of ribosome }\end{array}$ & $\begin{array}{l}\text { Translational elongation; } \\
\text { translational initiation; } \\
\text { translational termination }\end{array}$ & 2.7 \\
\hline NM_006989.5 & RASA4 & $\begin{array}{l}\text { RAS p } 21 \text { protein } \\
\text { activator } 4\end{array}$ & $\begin{array}{l}\text { GTPase activator activity; } \\
\text { phospholipid binding }\end{array}$ & $\begin{array}{l}\text { Intracellular signal transduction; } \\
\text { positive regulation of GTPase } \\
\text { activity; regulation of small } \\
\text { GTPase mediated signal } \\
\text { transduction }\end{array}$ & 2.6 \\
\hline NM_000983.3 & RPL22 & Ribosomal protein L22 & $\begin{array}{l}\text { RNA binding; heparin } \\
\text { binding; structural } \\
\text { constituent of ribosome }\end{array}$ & $\begin{array}{l}\text { Alpha-beta T cell differentiation; } \\
\text { translational elongation; } \\
\text { translational initiation; } \\
\text { translational termination }\end{array}$ & 2.6 \\
\hline NM_019059.3 & TOMM7 & $\begin{array}{l}\text { Translocase of outer } \\
\text { mitochondrial } \\
\text { membrane } 7 \text { homolog } \\
\text { (yeast) }\end{array}$ & $\begin{array}{l}\text { Protein transmembrane } \\
\text { transporter activity }\end{array}$ & $\begin{array}{l}\text { Cellular protein metabolic process; } \\
\text { protein import into mitochondrial } \\
\text { matrix; protein targeting to } \\
\text { mitochondrion }\end{array}$ & 2.6 \\
\hline NM_031157.2 & HNRNPA1 & $\begin{array}{l}\text { Heterogeneous nuclear } \\
\text { ribonucleoprotein A1 }\end{array}$ & $\begin{array}{l}\text { Nucleotide binding; } \\
\text { single-stranded DNA } \\
\text { binding; single-stranded } \\
\text { RNA binding }\end{array}$ & $\begin{array}{l}\text { RNA export from nucleus; mRNA } \\
\text { splicing, via spliceosome; mRNA } \\
\text { transport; nuclear import }\end{array}$ & 2.5 \\
\hline NM_001828.5 & CLC & $\begin{array}{l}\text { Charcot-Leyden crystal } \\
\text { galectin }\end{array}$ & $\begin{array}{l}\text { Carbohydrate binding; } \\
\text { carboxylesterase activity; } \\
\text { lysophospholipase activity }\end{array}$ & $\begin{array}{l}\text { Lipid catabolic process; } \\
\text { multicellular organismal } \\
\text { development }\end{array}$ & 2.4 \\
\hline NM_032901.3 & COX14 & $\begin{array}{l}\text { Cytochrome c oxidase } \\
\text { assembly homolog } 14 \\
\text { (S. cerevisiae) }\end{array}$ & $\begin{array}{l}\text { Plays a role in the } \\
\text { assembly or stability of the } \\
\text { cytochrome c oxidase } \\
\text { complex (COX) }\end{array}$ & $\begin{array}{l}\text { Mitochondrial respiratory chain } \\
\text { complex IV assembly }\end{array}$ & 2.3 \\
\hline NM_024960.4 & PANK2 & Pantothenate kinase 2 & $\begin{array}{l}\text { ATP binding; } \\
\text { pantothenate kinase } \\
\text { activity }\end{array}$ & $\begin{array}{l}\text { Cell death; coenzyme A } \\
\text { biosynthetic process; coenzyme } \\
\text { biosynthetic process; pantothenate } \\
\text { metabolic process }\end{array}$ & 2.3 \\
\hline NR_002309.1 & RPS26P11 & $\begin{array}{l}\text { Ribosomal protein S26 } \\
\text { pseudogene } 11\end{array}$ & $\begin{array}{l}\text { Structural constituent of } \\
\text { ribosome }\end{array}$ & Translation & 2.3 \\
\hline NM_005003.2 & NDUFAB1 & $\begin{array}{l}\text { NADH dehydrogenase } \\
\text { (ubiquinone) } 1 \text {, } \\
\text { alpha/beta subcomplex, } \\
1,8 \mathrm{kDa}\end{array}$ & $\begin{array}{l}\text { NADH dehydrogenase } \\
\text { (ubiquinone) activity; } \\
\text { ACP phosphopantetheine } \\
\text { attachment site binding } \\
\text { involved in fatty acid } \\
\text { biosynthetic process; fatty } \\
\text { acid binding; calcium ion } \\
\text { binding }\end{array}$ & $\begin{array}{l}\text { Cellular metabolic process; protein } \\
\text { lipoylation; small molecule } \\
\text { metabolic process; respiratory } \\
\text { electron transport chain; fatty acid } \\
\text { biosynthetic process; } \\
\text { mitochondrial electron transport, } \\
\text { NADH to ubiquinone }\end{array}$ & 2.3 \\
\hline
\end{tabular}


TABLE 2: Continued.

\begin{tabular}{|c|c|c|c|c|c|}
\hline $\begin{array}{l}\text { NCBI reference } \\
\text { sequence }\end{array}$ & Gene symbol & Gene name & Molecular function & Biological process & Fold change \\
\hline NM_152851.2 & MS4A6A & $\begin{array}{l}\text { Membrane-spanning } \\
\text { 4-domains, subfamily } \\
\text { A, member 6A }\end{array}$ & $\begin{array}{l}\text { May be involved in signal } \\
\text { transduction as a } \\
\text { component of a } \\
\text { multimeric receptor } \\
\text { complex }\end{array}$ & - & 2.3 \\
\hline NM_004269.3 & MED27 & $\begin{array}{l}\text { Mediator complex } \\
\text { subunit } 27\end{array}$ & $\begin{array}{l}\text { Transcription coactivator } \\
\text { activity }\end{array}$ & $\begin{array}{l}\text { Regulation of transcription from } \\
\text { RNA polymerase II promoter; } \\
\text { stem cell maintenance; } \\
\text { transcription initiation from RNA } \\
\text { polymerase II promoter }\end{array}$ & 2.2 \\
\hline NR_015404.1 & C12orf47 & $\begin{array}{l}\text { MAPKAPK5 antisense } \\
\text { RNA } 1\end{array}$ & - & - & 2.2 \\
\hline NM_001865.3 & COX7A2 & $\begin{array}{l}\text { Cytochrome c oxidase } \\
\text { subunit VIIa } \\
\text { polypeptide } 2 \text { (liver) }\end{array}$ & $\begin{array}{l}\text { Cytochrome-c oxidase } \\
\text { activity; electron carrier } \\
\text { activity }\end{array}$ & Oxidative phosphorylation & 2.2 \\
\hline NM_004374.3 & COX6C & $\begin{array}{l}\text { Cytochrome c oxidase } \\
\text { subunit VIc }\end{array}$ & $\begin{array}{l}\text { Cytochrome-c oxidase } \\
\text { activity }\end{array}$ & $\begin{array}{l}\text { Respiratory electron transport } \\
\text { chain; small molecule metabolic } \\
\text { process }\end{array}$ & 2.2 \\
\hline NM_002984.2 & CCL4 & $\begin{array}{l}\text { Chemokine }(\mathrm{C}-\mathrm{C} \\
\text { motif) ligand } 4\end{array}$ & Chemokine activity & $\begin{array}{l}\text { Cell adhesion; cell-cell signaling; } \\
\text { chemotaxis; immune response; } \\
\text { inflammatory response; positive } \\
\text { regulation of calcium ion } \\
\text { transport; positive regulation of } \\
\text { calcium-mediated signaling; } \\
\text { positive regulation of natural killer } \\
\text { cell chemotaxis; } \\
\text { response to toxic substance; } \\
\text { response to virus; signal } \\
\text { transduction }\end{array}$ & 2.2 \\
\hline NM_014060.2 & MCTS1 & $\begin{array}{l}\text { Malignant T cell } \\
\text { amplified sequence } 1\end{array}$ & RNA binding & $\begin{array}{l}\text { Cell cycle; positive regulation of } \\
\text { cell proliferation; regulation of } \\
\text { growth; regulation of } \\
\text { transcription, DNA-dependent; } \\
\text { response to DNA damage stimulus } \\
\text { transcription, DNA-dependent }\end{array}$ & 2.1 \\
\hline NM_004832.2 & GSTO1 & $\begin{array}{l}\text { Glutathione } \\
\text { S-transferase omega } 1\end{array}$ & $\begin{array}{l}\text { Glutathione } \\
\text { dehydrogenase } \\
\text { (ascorbate) activity; } \\
\text { glutathione transferase } \\
\text { activity; methylarsonate } \\
\text { reductase activity }\end{array}$ & $\begin{array}{l}\text { L-ascorbic acid metabolic process; } \\
\text { glutathione derivative biosynthetic } \\
\text { process; negative regulation of } \\
\text { ryanodine-sensitive } \\
\text { calcium-release channel activity; } \\
\text { positive regulation of } \\
\text { ryanodine-sensitive } \\
\text { calcium-release channel activity; } \\
\text { positive regulation of skeletal } \\
\text { muscle contraction by regulation } \\
\text { of release of sequestered calcium } \\
\text { ion; regulation of cardiac muscle } \\
\text { contraction by regulation of the } \\
\text { release of sequestered calcium ion; } \\
\text { xenobiotic catabolic process }\end{array}$ & 2.1 \\
\hline NM_001867.2 & COX7C & $\begin{array}{l}\text { Cytochrome c oxidase } \\
\text { subunit VIIc }\end{array}$ & $\begin{array}{l}\text { Cytochrome-c oxidase } \\
\text { activity }\end{array}$ & $\begin{array}{l}\text { Respiratory electron transport } \\
\text { chain; small molecule metabolic } \\
\text { process }\end{array}$ & 2.1 \\
\hline
\end{tabular}


TABle 2: Continued.

\begin{tabular}{|c|c|c|c|c|c|}
\hline $\begin{array}{l}\text { NCBI reference } \\
\text { sequence }\end{array}$ & Gene symbol & Gene name & Molecular function & Biological process & Fold change \\
\hline NM_014206.3 & C11orf10 & $\begin{array}{l}\text { Transmembrane } \\
\text { protein } 258\end{array}$ & - & - & 2.1 \\
\hline NM_002413.4 & MGST2 & $\begin{array}{l}\text { Microsomal } \\
\text { glutathione } \\
\text { S-transferase } 2\end{array}$ & $\begin{array}{l}\text { Enzyme activator activity; } \\
\text { glutathione peroxidase } \\
\text { activity; glutathione } \\
\text { transferase activity; } \\
\text { leukotriene-C4 synthase } \\
\text { activity }\end{array}$ & $\begin{array}{l}\text { Glutathione biosynthetic process; } \\
\text { glutathione derivative biosynthetic } \\
\text { process; leukotriene biosynthetic } \\
\text { process; positive regulation of } \\
\text { catalytic activity; xenobiotic } \\
\text { metabolic process }\end{array}$ & 2.1 \\
\hline NM_001124767.1 & C3orf78 & $\begin{array}{l}\text { Small integral } \\
\text { membrane protein } 4\end{array}$ & - & - & 2.1 \\
\hline NM_152398.2 & OCIAD2 & $\begin{array}{l}\text { OCIA domain } \\
\text { containing } 2\end{array}$ & - & - & 2.1 \\
\hline NM_002488.4 & NDUFA2 & $\begin{array}{l}\text { NADH dehydrogenase } \\
\text { (ubiquinone) } 1 \text { alpha } \\
\text { subcomplex, } 2,8 \mathrm{kDa}\end{array}$ & $\begin{array}{l}\text { NADH dehydrogenase } \\
\text { (ubiquinone) activity }\end{array}$ & $\begin{array}{l}\text { Mitochondrial electron transport, } \\
\text { NADH to ubiquinone small } \\
\text { molecule metabolic process }\end{array}$ & 2.1 \\
\hline NM_004528.3 & MGST3 & $\begin{array}{l}\text { Microsomal } \\
\text { glutathione } \\
\text { S-transferase } 3\end{array}$ & $\begin{array}{l}\text { Glutathione peroxidase } \\
\text { activity; } \\
\text { glutathione transferase } \\
\text { activity }\end{array}$ & $\begin{array}{l}\text { Glutathione derivative } \\
\text { biosynthetic process; lipid } \\
\text { metabolic process; signal } \\
\text { transduction; small molecule } \\
\text { metabolic process } \\
\text { xenobiotic metabolic process }\end{array}$ & 2.0 \\
\hline NM_003095.2 & SNRPF & $\begin{array}{l}\text { Small nuclear } \\
\text { ribonucleoprotein } \\
\text { polypeptide F }\end{array}$ & RNA binding & $\begin{array}{l}\text { Histone mRNA metabolic process; } \\
\text { mRNA } 3^{\prime} \text {-end processing } \\
\text { ncRNA metabolic process; } \\
\text { spliceosomal snRNP assembly; } \\
\text { termination of RNA polymerase II } \\
\text { transcription }\end{array}$ & 2.0 \\
\hline NM_005213.3 & CSTA & Cystatin A (stefin A) & $\begin{array}{l}\text { Cysteine-type } \\
\text { endopeptidase inhibitor } \\
\text { activity; protein binding, } \\
\text { bridging } \\
\text { structural molecule } \\
\text { activity }\end{array}$ & $\begin{array}{l}\text { Cell-cell adhesion; keratinocyte } \\
\text { differentiation; peptide } \\
\text { cross-linking }\end{array}$ & 2.0 \\
\hline NM_033318.4 & C22orf32 & $\begin{array}{l}\text { Single-pass membrane } \\
\text { protein with } \\
\text { aspartate-rich tail } 1\end{array}$ & - & - & 2.0 \\
\hline NM_053035.2 & MRPS33 & $\begin{array}{l}\text { Mitochondrial } \\
\text { ribosomal protein S33 }\end{array}$ & $\begin{array}{l}\text { Structural constituent of } \\
\text { ribosome }\end{array}$ & Translation & 2.0 \\
\hline ВС014670.1 & LOC147727 & $\begin{array}{l}\text { Hypothetical protein } \\
\text { LOC147727, mRNA } \\
\text { (cDNA clone IMAGE: } \\
\text { 4864993), partial cds }\end{array}$ & - & - & 2.0 \\
\hline NM_001014.4 & RPS10 & Ribosomal protein $S 10$ & Protein binding & $\begin{array}{l}\text { Translational elongation; } \\
\text { translational initiation; } \\
\text { translational termination; viral } \\
\text { transcription }\end{array}$ & 2.0 \\
\hline NM_001130710.1 & LSM5 & $\begin{array}{l}\text { LSM5 homolog, } \\
\text { associated U6 small } \\
\text { nuclear RNA (S. } \\
\text { cerevisiae) }\end{array}$ & RNA binding & $\begin{array}{l}\text { RNA splicing; exonucleolytic } \\
\text { nuclear-transcribed mRNA } \\
\text { catabolic process involved in } \\
\text { deadenylation-dependent decay; } \\
\text { mRNA processing }\end{array}$ & 2.0 \\
\hline
\end{tabular}


TABLE 2: Continued.

\begin{tabular}{|c|c|c|c|c|c|}
\hline $\begin{array}{l}\text { NCBI reference } \\
\text { sequence }\end{array}$ & Gene symbol & Gene name & Molecular function & Biological process & Fold change \\
\hline NM_002801.3 & PSMB10 & $\begin{array}{l}\text { Proteasome (prosome, } \\
\text { macropain) subunit, } \\
\text { beta type, } 10\end{array}$ & $\begin{array}{l}\text { Threonine-type } \\
\text { endopeptidase activity }\end{array}$ & $\begin{array}{l}\text { DNA damage response, signal } \\
\text { transduction by p53 class mediator } \\
\text { resulting in cell cycle arrest; G1/S } \\
\text { transition of mitotic cell cycle; T } \\
\text { cell proliferation; } \\
\text { anaphase-promoting } \\
\text { complex-dependent proteasomal } \\
\text { ubiquitin-dependent protein } \\
\text { catabolic process; apoptotic } \\
\text { process; cell morphogenesis; gene } \\
\text { expression; humoral immune } \\
\text { response; mRNA metabolic } \\
\text { process; negative regulation of } \\
\text { apoptotic process; negative } \\
\text { regulation of ubiquitin-protein } \\
\text { ligase activity involved in mitotic } \\
\text { cell cycle; positive regulation of } \\
\text { ubiquitin-protein ligase activity } \\
\text { involved in mitotic cell cycle; } \\
\text { protein polyubiquitination; } \\
\text { regulation of cellular amino acid } \\
\text { metabolic process; small molecule } \\
\text { metabolic process }\end{array}$ & 2.0 \\
\hline NM_014044.5 & UNC50 & $\begin{array}{l}\text { Unc-50 homolog }(\mathrm{C} . \\
\text { elegans })\end{array}$ & RNA binding & $\begin{array}{l}\text { Cell surface receptor signaling } \\
\text { pathway; protein transport }\end{array}$ & 2.0 \\
\hline NM_032747.3 & USMG5 & $\begin{array}{l}\text { Up-regulated during } \\
\text { skeletal muscle growth } \\
5 \text { homolog (mouse) }\end{array}$ & $\begin{array}{l}\text { Plays a critical role in } \\
\text { maintaining the ATP } \\
\text { synthase population in } \\
\text { mitochondria }\end{array}$ & ( & 2.0 \\
\hline NM_001001330.2 & REEP3 & $\begin{array}{l}\text { Receptor accessory } \\
\text { protein } 3\end{array}$ & $\begin{array}{l}\text { May enhance the cell } \\
\text { surface expression of } \\
\text { odorant receptors }\end{array}$ & - & 2.0 \\
\hline NM_004074.2 & COX8A & $\begin{array}{l}\text { Cytochrome c oxidase } \\
\text { subunit VIIIA } \\
\text { (ubiquitous) }\end{array}$ & $\begin{array}{l}\text { Cytochrome-c oxidase } \\
\text { activity }\end{array}$ & $\begin{array}{l}\text { Respiratory electron transport } \\
\text { chain; small molecule metabolic } \\
\text { process }\end{array}$ & 2.0 \\
\hline NM_002493.4 & NDUFB6 & $\begin{array}{l}\text { NADH dehydrogenase } \\
\text { (ubiquinone) } 1 \text { beta } \\
\text { subcomplex, } 6,17 \mathrm{kDa}\end{array}$ & $\begin{array}{l}\text { NADH dehydrogenase } \\
\text { (ubiquinone) activity }\end{array}$ & $\begin{array}{l}\text { Mitochondrial electron transport, } \\
\text { NADH to ubiquinone; small } \\
\text { molecule metabolic process }\end{array}$ & 2.0 \\
\hline NM_032273.3 & TMEM126A & $\begin{array}{l}\text { Transmembrane } \\
\text { protein } 126 \mathrm{~A}\end{array}$ & - & Optic nerve development & 2.0 \\
\hline
\end{tabular}

“-": lacking item.

B, and iron sulfur (Ip)) gene encoding for a subunit of mitochondrial complex II (succinate: ubiquinone oxidoreductase) was significantly upregulated. This subunit is responsible for transferring electrons from succinate to ubiquinone (coenzyme Q). Complex II of the respiratory chain, which is specifically involved in the oxidation of succinate, carries electrons from FADH to CoQ. Of note, also 3 genes, UQCRQ, UQCRFS1, and UQCRH, encoding for subunits of complex III (ubiquinol-cytochrome c oxidoreductase), were upregulated with a mean $\mathrm{FC}=1.60$. This complex plays a critical role in biochemical generation of ATP, contributing to the generation of electrochemical potential by catalyzing the electron transfer reaction from ubiquinol to cytochrome $c$ coupled with proton translocation across the membrane. Lines of evidence report that in mouse models some of the promoters of ubiquinol-cytochrome $\mathrm{c}$ reductase subunit are able to be targeted by MECP2 protein, contributing to the development of the pathology [30].

Furthermore, the cytochrome $c$ gene (CYCS) together with genes encoding subunits of mitochondrial complex IV (cytochrome c oxidase) (COX14, COX7A2, COX6C, COX7C, and $C O X 8 A$ ) was upregulated with a mean FC of circa 1.5. Of note is the upregulation of cytochrome $c$ gene. The encoded protein accepts electrons from cytochrome $b$ and transfers them to the cytochrome oxidase complex. This protein is also involved in initiation of apoptosis and this would be in line 
TABLE 3: Genes down-regulated in RTT patients by LIMMA and SAM analyses.

\begin{tabular}{|c|c|c|c|c|c|}
\hline $\begin{array}{l}\text { NCBI reference } \\
\text { sequence }\end{array}$ & Gene symbol & Gene name & Molecular function & Biological process & Fold change \\
\hline NM_170601.4 & SIAE & Sialic acid acetylesterase & $\begin{array}{l}\text { Sialate } \mathrm{O} \text {-acetylesterase } \\
\text { activity }\end{array}$ & - & -2.3 \\
\hline NR_002312.1 & RPPH1 & $\begin{array}{l}\text { Ribonuclease P RNA } \\
\text { component H1 }\end{array}$ & - & - & -2.2 \\
\hline NM_005322.2 & HIST1H1B & Histone cluster $1, \mathrm{H} 1 \mathrm{~b}$ & DNA binding & Nucleosome assembly & -1.8 \\
\hline NM_000902.3 & MME & $\begin{array}{l}\text { Membrane } \\
\text { metalloendopeptidase }\end{array}$ & $\begin{array}{l}\text { Metalloendopeptidase } \\
\text { activity }\end{array}$ & Proteolysis & -1.8 \\
\hline NM_032047.4 & B3GNT5 & $\begin{array}{l}\text { UDP-GlcNAc: betaGal } \\
\text { beta-1,3-N- } \\
\text { acetylglucosaminyltransferase } \\
5\end{array}$ & $\begin{array}{l}\text { Galactosyltransferase } \\
\text { activity }\end{array}$ & $\begin{array}{l}\text { Glycolipid biosynthetic process; } \\
\text { posttranslational protein } \\
\text { modification }\end{array}$ & -1.7 \\
\hline NM_003513.2 & HIST1H2AB & Histone cluster $1, \mathrm{H} 2 \mathrm{ab}$ & DNA binding & Nucleosome assembly & -1.7 \\
\hline NR_002562.1 & SNORD28 & $\begin{array}{l}\text { Small nucleolar RNA, C/D } \\
\text { box } 28\end{array}$ & - & - & -1.5 \\
\hline NM_004668.2 & MGAM & $\begin{array}{l}\text { Maltase-glucoamylase } \\
\text { (alpha-glucosidase) }\end{array}$ & $\begin{array}{l}\text { Alpha-glucosidase } \\
\text { activity; amylase } \\
\text { activity }\end{array}$ & Carbohydrate metabolic process & -1.5 \\
\hline NM_012081.5 & ELL2 & $\begin{array}{l}\text { Elongation factor, RNA } \\
\text { polymerase II, } 2\end{array}$ & 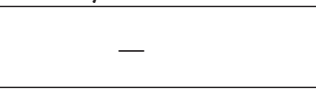 & $\begin{array}{l}\text { Regulation of transcription, } \\
\text { DNA-dependent }\end{array}$ & -1.4 \\
\hline NM_021066.2 & HIST1H2AJ & Histone cluster 1, H2aj & DNA binding & nucleosome assembly & -1.4 \\
\hline NM_002424.2 & MMP8 & $\begin{array}{l}\text { Matrix metallopeptidase } 8 \\
\text { (neutrophil collagenase) }\end{array}$ & $\begin{array}{l}\text { Metalloendopeptidase } \\
\text { activity; zinc ion } \\
\text { binding }\end{array}$ & Proteolysis & -1.4 \\
\hline NM_004994.2 & MMP9 & $\begin{array}{l}\text { Matrix metallopeptidase } 9 \\
\text { (gelatinase } \mathrm{B}, 92 \mathrm{kDa} \text {, } \\
\text { gelatinase, } 92 \mathrm{kDa} \text {, type IV } \\
\text { collagenase) }\end{array}$ & $\begin{array}{l}\text { Collagen binding; } \\
\text { metalloendopeptidase } \\
\text { activity; zinc ion } \\
\text { binding }\end{array}$ & $\begin{array}{l}\text { Collagen catabolic process; } \\
\text { extracellular matrix disassembly; } \\
\text { positive regulation of apoptotic } \\
\text { process; proteolysis }\end{array}$ & -1.4 \\
\hline NM_003533.2 & HIST1H3I & Histone cluster $1, \mathrm{H} 3 \mathrm{i}$ & DNA binding & $\begin{array}{l}\text { Nucleosome assembly; regulation } \\
\text { of gene silencing }\end{array}$ & -1.3 \\
\hline NG_000861.4 & GK3P & Glycerol kinase 3 pseudogene & $\begin{array}{l}\text { ATP binding; glycerol } \\
\text { kinase activity }\end{array}$ & $\begin{array}{l}\text { Catabolic process; glycerol } \\
\text { metabolic process }\end{array}$ & -1.3 \\
\hline NR_033423.1 & LOC1720 & $\begin{array}{l}\text { Dihydrofolate reductase } \\
\text { pseudogene }\end{array}$ & ( & ( & -1.3 \\
\hline NM_003521.2 & HIST1H2BM & Histone cluster 1, H2bm & DNA binding & Nucleosome assembly & -13 \\
\hline NM_002417.4 & MKI67 & $\begin{array}{l}\text { Antigen identified by } \\
\text { monoclonal antibody Ki- } 67\end{array}$ & ATP binding & $\begin{array}{l}\text { DNA metabolic process; cell } \\
\text { proliferation; cellular response to } \\
\text { heat; meiosis; organ regeneration }\end{array}$ & -1.2 \\
\hline NM_020406.2 & CD177 & CD177 molecule & - & $\begin{array}{l}\text { Blood coagulation; leukocyte } \\
\text { migration }\end{array}$ & -1.2 \\
\hline NM_001039841.1 & ARHGAP11B & $\begin{array}{l}\text { Rho GTPase activating } \\
\text { protein } 11 \mathrm{~B}\end{array}$ & $\begin{array}{l}\text { GTPase activator } \\
\text { activity }\end{array}$ & $\begin{array}{l}\text { Positive regulation of GTPase } \\
\text { activity; regulation of small } \\
\text { GTPase mediated signal } \\
\text { transduction; small GTPase } \\
\text { mediated signal transduction }\end{array}$ & -1.2 \\
\hline NM_001004690.1 & OR2M5 & $\begin{array}{l}\text { Olfactory receptor, family } 2 \text {, } \\
\text { subfamily } \mathrm{M} \text {, member } 5\end{array}$ & $\begin{array}{l}\text { G-protein coupled } \\
\text { receptor activity; } \\
\text { olfactory receptor } \\
\text { activity }\end{array}$ & $\begin{array}{l}\text { Detection of chemical stimulus } \\
\text { involved in sensory perception of } \\
\text { smell }\end{array}$ & -1.2 \\
\hline NM_052966.3 & FAM129A & $\begin{array}{l}\text { Family with sequence } \\
\text { similarity } 129, \text { member A }\end{array}$ & - & $\begin{array}{l}\text { Negative regulation of protein } \\
\text { phosphorylation; positive } \\
\text { regulation of protein } \\
\text { phosphorylation; positive } \\
\text { regulation of translation; response } \\
\text { to endoplasmic reticulum stress }\end{array}$ & -1.2 \\
\hline
\end{tabular}


TABle 3: Continued.

\begin{tabular}{|c|c|c|c|c|c|}
\hline $\begin{array}{l}\text { NCBI reference } \\
\text { sequence }\end{array}$ & Gene symbol & Gene name & Molecular function & Biological process & Fold change \\
\hline NM_001067.3 & TOP2A & $\begin{array}{l}\text { Topoisomerase (DNA) II } \\
\text { alpha } 170 \mathrm{kDa}\end{array}$ & $\begin{array}{l}\text { ATP binding; DNA } \\
\text { binding, bending; } \\
\text { chromatin binding; } \\
\text { drug binding; } \\
\text { magnesium ion } \\
\text { binding; ubiquitin } \\
\text { binding }\end{array}$ & $\begin{array}{l}\text { DNA ligation; DNA repair; DNA } \\
\text { topological change; } \\
\text { DNA-dependent DNA replication; } \\
\text { apoptotic chromosome } \\
\text { condensation; mitotic cell cycle; } \\
\text { phosphatidylinositol-mediated } \\
\text { signaling; positive regulation of } \\
\text { apoptotic process; positive } \\
\text { regulation of retroviral genome } \\
\text { replication; positive regulation of } \\
\text { transcription from RNA } \\
\text { polymerase II promoter; sister } \\
\text { chromatid segregation }\end{array}$ & -1.2 \\
\hline NM_021018.2 & HIST1H3F & Histone cluster $1, \mathrm{H} 3 \mathrm{f}$ & DNA binding & $\begin{array}{l}\text { S phase; blood coagulation; } \\
\text { nucleosome assembly; } \\
\text { regulation of gene silencing }\end{array}$ & -1.2 \\
\hline NM_182707.2 & PSG8 & $\begin{array}{l}\text { Pregnancy specific } \\
\text { beta-1-glycoprotein } 8\end{array}$ & $\begin{array}{l}\text { The human } \\
\text { pregnancy-specific } \\
\text { glycoproteins (PSGs) } \\
\text { are a group of } \\
\text { molecules that are } \\
\text { mainly produced by the } \\
\text { placental } \\
\text { syncytiotrophoblasts } \\
\text { during pregnancy. PSGs } \\
\text { comprise a subgroup of } \\
\text { the carcinoembryonic } \\
\text { antigen (CEA) family, } \\
\text { which } \\
\text { belongs to the } \\
\text { immunoglobulin } \\
\text { superfamily. }\end{array}$ & Female pregnancy & -1.2 \\
\hline NM_003535.2 & HIST1H3J & Histone cluster $1, \mathrm{H} 3 \mathrm{j}$ & DNA binding & $\begin{array}{l}\text { S phase; blood coagulation; } \\
\text { nucleosome assembly; } \\
\text { regulation of gene silencing }\end{array}$ & -1.2 \\
\hline NM_004566.3 & PFKFB3 & $\begin{array}{l}\text { 6-Phosphofructo-2- } \\
\text { kinase/fructose-2,6- } \\
\text { biphosphatase } \\
3\end{array}$ & $\begin{array}{l}\text { 6-Phosphofructo-2- } \\
\text { kinase activity; ATP } \\
\text { binding; fructose-2,6- } \\
\text { bisphosphate } \\
\text { 2-phosphatase activity }\end{array}$ & $\begin{array}{l}\text { Fructose metabolic process; } \\
\text { glycolysis; small molecule } \\
\text { metabolic process }\end{array}$ & -1.2 \\
\hline NM_016448.2 & DTL & $\begin{array}{l}\text { Denticleless E3 } \\
\text { ubiquitin-protein ligase } \\
\text { homolog (Drosophila) }\end{array}$ & - & $\begin{array}{l}\text { DNA replication; G2 DNA } \\
\text { damage checkpoint; protein } \\
\text { monoubiquitination; protein } \\
\text { polyubiquitination; } \\
\text { ubiquitin-dependent protein } \\
\text { catabolic process }\end{array}$ & -1.2 \\
\hline NG_001019.5 & IGHM & $\begin{array}{l}\text { Immunoglobulin heavy } \\
\text { constant mu }\end{array}$ & Antigen binding & Immune response & -1.2 \\
\hline NR_002907.2 & SNORA73A & $\begin{array}{l}\text { Small nucleolar RNA, H/ACA } \\
\text { box } 73 \mathrm{~A}\end{array}$ & - & - & -1.2 \\
\hline
\end{tabular}

“-": lacking item.

with previous studies that have shown a possible involvement of apoptosis in RTT [31,32], although only few studies have investigated the role of apoptosis in RTT and the current literature is still controversial. In addition, several subunits of complex IV were upregulated. It receives an electron from each of the four cytochrome c molecules and transfers them to one oxygen molecule, converting molecular oxygen to two molecules of water. In the process, via a protons translocation, 
TABLE 4: GO analysis of genes reported to be deregulated in PBMC of RTT patients.

\begin{tabular}{|c|c|c|c|}
\hline Term & Description & $P$ value & Fold enrichment \\
\hline \multicolumn{4}{|c|}{ Cluster 1} \\
\hline GO:0022900 & Electron transport chain & $2.0 \times 10^{-12}$ & 9.01 \\
\hline GO:0006091 & $\begin{array}{l}\text { Generation of precursor metabolites and } \\
\text { energy }\end{array}$ & $1.7 \times 10^{-12}$ & 5.06 \\
\hline GO:0045333 & Cellular respiration & $2.7 \times 10^{-12}$ & 9.71 \\
\hline GO:0006120 & $\begin{array}{l}\text { Mitochondrial electron transport, NADH } \\
\text { to ubiquinone }\end{array}$ & $4.9 \times 10^{-12}$ & 16.32 \\
\hline GO:0022904 & Respiratory electron transport chain & $1.8 \times 10^{-11}$ & 12.04 \\
\hline GO:0006119 & Oxidative phosphorylation & $2.0 \times 10^{-11}$ & 9.17 \\
\hline GO:0042775 & $\begin{array}{l}\text { Mitochondrial ATP synthesis coupled } \\
\text { electron transport }\end{array}$ & $2.0 \times 10^{-11}$ & 12.99 \\
\hline GO:0042773 & ATP synthesis coupled electron transport & $2.0 \times 10^{-11}$ & 12.99 \\
\hline GO:0015980 & $\begin{array}{l}\text { Energy derivation by oxidation of organic } \\
\text { compounds }\end{array}$ & $3.4 \times 10^{-9}$ & 6.54 \\
\hline GO:0055114 & Oxidation reduction & $1.5 \times 10^{-8}$ & 3.01 \\
\hline \multicolumn{4}{|c|}{ Cluster 2} \\
\hline GO:0006626 & Protein targeting to mitochondrion & $4.3 \times 10^{-3}$ & 8.81 \\
\hline GO:0070585 & Protein localization in mitochondrion & $4.3 \times 10^{-3}$ & 8.81 \\
\hline GO:0045039 & $\begin{array}{l}\text { Protein import into mitochondrial inner } \\
\text { membrane }\end{array}$ & $7.5 \times 10^{-3}$ & 28.54 \\
\hline GO:0007007 & $\begin{array}{l}\text { Inner mitochondrial membrane } \\
\text { organization }\end{array}$ & $2.8 \times 10^{-2}$ & 19.03 \\
\hline GO:0006839 & Mitochondrial transport & $3.1 \times 10^{-2}$ & 4.96 \\
\hline \multicolumn{4}{|c|}{ Cluster 3} \\
\hline GO:0051436 & $\begin{array}{l}\text { Negative regulation of ubiquitin-protein } \\
\text { ligase activity during mitotic cell cycle }\end{array}$ & $1.8 \times 10^{-4}$ & 7.24 \\
\hline GO:0051444 & $\begin{array}{l}\text { Negative regulation of ubiquitin-protein } \\
\text { ligase activity }\end{array}$ & $2.1 \times 10^{-4}$ & 7.03 \\
\hline GO:0051352 & Negative regulation of ligase activity & $2.1 \times 10^{-4}$ & 7.03 \\
\hline GO:0051437 & $\begin{array}{l}\text { Positive regulation of ubiquitin-protein } \\
\text { ligase activity during mitotic cell cycle }\end{array}$ & $2.4 \times 10^{-4}$ & 6.92 \\
\hline GO:0051443 & $\begin{array}{l}\text { Positive regulation of ubiquitin-protein } \\
\text { ligase activity }\end{array}$ & $2.8 \times 10^{-4}$ & 6.73 \\
\hline GO:0051439 & $\begin{array}{l}\text { Regulation of ubiquitin-protein ligase } \\
\text { activity during mitotic cell cycle }\end{array}$ & $3.0 \times 10^{-4}$ & 6.63 \\
\hline GO:0051351 & Positive regulation of ligase activity & $3.7 \times 10^{-4}$ & 6.45 \\
\hline GO:0051438 & $\begin{array}{l}\text { Regulation of ubiquitin-protein ligase } \\
\text { activity }\end{array}$ & $6.2 \times 10^{-4}$ & 6.04 \\
\hline GO:0051340 & Regulation of ligase activity & $8.4 \times 10^{-4}$ & 5.81 \\
\hline GO:0043086 & Negative regulation of catalytic activity & $8.4 \times 10^{-3}$ & 2.78 \\
\hline GO:0044092 & Negative regulation of molecular function & $9.6 \times 10^{-3}$ & 2.56 \\
\hline \multicolumn{4}{|c|}{ Cluster 4} \\
\hline GO:0031145 & $\begin{array}{l}\text { Anaphase-promoting } \\
\text { complex-dependent proteasomal } \\
\text { ubiquitin-dependent protein catabolic } \\
\text { process }\end{array}$ & $1.8 \times 10^{-4}$ & 7.24 \\
\hline GO:0010498 & Proteasomal protein catabolic process & $4.4 \times 10^{-3}$ & 4.62 \\
\hline GO:0043161 & $\begin{array}{l}\text { Proteasomal ubiquitin-dependent protein } \\
\text { catabolic process }\end{array}$ & $4.4 \times 10^{-3}$ & 4.62 \\
\hline \multicolumn{4}{|c|}{ Cluster 5} \\
\hline GO:0031397 & $\begin{array}{l}\text { Negative regulation of protein } \\
\text { ubiquitination }\end{array}$ & $4.1 \times 10^{-4}$ & 6.36 \\
\hline
\end{tabular}


TABle 4: Continued.

\begin{tabular}{|c|c|c|c|}
\hline Term & Description & $P$ value & Fold enrichment \\
\hline GO:0031400 & $\begin{array}{l}\text { Negative regulation of protein } \\
\text { modification process }\end{array}$ & $9.2 \times 10^{-4}$ & 4.68 \\
\hline GO:0031398 & $\begin{array}{l}\text { Positive regulation of protein } \\
\text { ubiquitination }\end{array}$ & $1.0 \times 10^{-3}$ & 5.61 \\
\hline GO:0032269 & $\begin{array}{l}\text { Negative regulation of cellular protein } \\
\text { metabolic process }\end{array}$ & $3.2 \times 10^{-3}$ & 3.58 \\
\hline GO:0031396 & Regulation of protein ubiquitination & $4.2 \times 10^{-3}$ & 4.71 \\
\hline GO:0051248 & $\begin{array}{l}\text { Negative regulation of protein metabolic } \\
\text { process }\end{array}$ & $4.4 \times 10^{-3}$ & 3.43 \\
\hline GO:0031401 & $\begin{array}{l}\text { Positive regulation of protein } \\
\text { modification process }\end{array}$ & $4.1 \times 10^{-2}$ & 2.98 \\
\hline GO:0032268 & $\begin{array}{l}\text { Regulation of cellular protein metabolic } \\
\text { process }\end{array}$ & $4.7 \times 10^{-2}$ & 2.08 \\
\hline \multicolumn{4}{|c|}{ Cluster 6} \\
\hline GO:0065003 & Macromolecular complex assembly & $1.4 \times 10^{-8}$ & 2.96 \\
\hline GO:0043933 & $\begin{array}{l}\text { Macromolecular complex subunit } \\
\text { organization }\end{array}$ & $9.9 \times 10^{-8}$ & 2.77 \\
\hline GO:0034622 & $\begin{array}{l}\text { Cellular macromolecular complex } \\
\text { assembly }\end{array}$ & $3.2 \times 10^{-6}$ & 3.63 \\
\hline GO:0034621 & $\begin{array}{l}\text { Cellular macromolecular complex } \\
\text { subunit organization }\end{array}$ & $2.6 \times 10^{-5}$ & 3.24 \\
\hline GO:0065004 & Protein-DNA complex assembly & $1.1 \times 10^{-4}$ & 6.12 \\
\hline GO:0034728 & Nucleosome organization & $5.2 \times 10^{-4}$ & 5.52 \\
\hline GO:0006461 & Protein complex assembly & $2.1 \times 10^{-3}$ & 2.37 \\
\hline GO:0070271 & Protein complex biogenesis & $2.1 \times 10^{-3}$ & 2.37 \\
\hline \multicolumn{4}{|c|}{ Cluster 7} \\
\hline GO:0006334 & Nucleosome assembly & $2.4 \times 10^{-4}$ & 6.12 \\
\hline GO:0031497 & Chromatin assembly & $3.1 \times 10^{-4}$ & 5.90 \\
\hline GO:0006323 & DNA packaging & $8.2 \times 10^{-4}$ & 4.76 \\
\hline GO:0006333 & Chromatin assembly or disassembly & $6.0 \times 10^{-3}$ & 4.04 \\
\hline \multicolumn{4}{|c|}{ Cluster 8} \\
\hline GO:0008380 & RNA splicing & $5.6 \times 10^{-6}$ & 3.77 \\
\hline GO:0006396 & RNA processing & $5.7 \times 10^{-6}$ & 2.82 \\
\hline GO:0006397 & mRNA processing & $1.5 \times 10^{-4}$ & 3.20 \\
\hline GO:0000398 & Nuclear mRNA splicing, via spliceosome & $2.0 \times 10^{-4}$ & 4.48 \\
\hline GO:0000377 & $\begin{array}{l}\text { RNA splicing, via transesterification } \\
\text { reactions with bulged adenosine as } \\
\text { nucleophile }\end{array}$ & $2.0 \times 10^{-4}$ & 4.48 \\
\hline GO:0000375 & $\begin{array}{l}\text { RNA splicing, via transesterification } \\
\text { reactions }\end{array}$ & $2.0 \times 10^{-4}$ & 4.48 \\
\hline GO:0016071 & mRNA metabolic process & $8.5 \times 10^{-4}$ & 2.78 \\
\hline \multicolumn{4}{|c|}{ Cluster 9} \\
\hline GO:0006412 & Translation & $2.6 \times 10^{-8}$ & 4.01 \\
\hline GO:0006414 & Translational elongation & $5.4 \times 10^{-5}$ & 5.93 \\
\hline \multicolumn{4}{|c|}{ Cluster 10} \\
\hline GO:0006367 & $\begin{array}{l}\text { Transcription initiation from RNA } \\
\text { polymerase II promoter }\end{array}$ & $1.1 \times 10^{-3}$ & 6.30 \\
\hline GO:0006352 & Transcription initiation & $4.5 \times 10^{-3}$ & 5.16 \\
\hline \multicolumn{4}{|c|}{ Cluster 11} \\
\hline GO:0006368 & $\begin{array}{l}\text { RNA elongation from RNA polymerase II } \\
\text { promoter }\end{array}$ & $1.1 \times 10^{-3}$ & 7.13 \\
\hline GO:0006354 & RNA elongation & $4.5 \times 10^{-3}$ & 6.71 \\
\hline
\end{tabular}


it is able to generate ATP. This data would suggest that RTT patients are in continuous new ATP synthesis and this could be a consequence of new protein synthesis.

Our data are in line with a previous work by Kriaucionis where the authors have analyzed the gene profile in the brain of RTT animal model [30]. They have shown that there were several mitochondrial abnormalities and an upregulation of both complexes I and III subunits. In particular they were also able to show a correlation between upregulation of complexes I and III and the animal symptoms severity with a significant increase in mitochondrial respiratory capacity and a reduction in respiratory efficiency. The defect appears to be associated with respiratory complex III, which is also upregulated in our study, and that containing the Uqcrcl protein. In addition it has been shown that MeCP2 binds to the promoter of the Uqcr gene in vivo and that Uqcr mRNA expression is elevated in brains of Mecp2-null mice that have acquired neurological symptoms and this is in line with our results.

Finally, we also observed in RTT PBMC an upregulation of mitochondrial complex V (ATP synthase) subunits (ATP5A1, ATP5EP2, ATP5J2, and ATP5O) together with ATPase inhibitory factor 1 gene (ATPIF1). Mitochondrial membrane ATP synthase is a master regulator of energy metabolism and cell fate; therefore, a misregulation of this gene can be associated with altered ATP production and cell metabolism. It is interesting to note that also the ATPase inhibitory factor 1 (ATPIF1) that inhibits the activity of the mitochondrial $\mathrm{H}^{+}$-ATP synthase was upregulated, and this lets us speculate the existence of an aberrant loop between making new ATP and inhibiting its production. In addition, recent findings indicate that $A T P I F 1$ has additional functions by promoting adaptive responses of cell to ROS [33], a condition (OS) that has been well documented to be present in RTT $[22,23]$.

Similarly, other genes related to the ATP synthesis showed significant expression changes (i.e., CYB5A, CYB561D2, ETFA, LDHB, PDHB, and SURF1). For instance, ETFA (electron transfer flavoprotein, alpha polypeptide) serves as a specific electron acceptor for several dehydrogenases and in mitochondria it shuttles electrons between primary flavoprotein dehydrogenases and the membrane-bound electron transfer flavoprotein ubiquinone oxidoreductase. In addition, $L D H B$ encodes lactate dehydrogenase $\mathrm{B}$, an enzyme that catalyzes the reversible conversion of lactate and pyruvate and $\mathrm{NAD}$ and NADH, in the glycolytic pathway, being therefore correlated with ATP generation. Of note is the upregulation of SURF1 (surfeit 1) gene that encodes a protein localized to the inner mitochondrial membrane and thought to be involved in the biogenesis of the cytochrome c oxidase complex.

Related to mitochondrial structure/organization, we found upregulation of 7 translocase genes (TIMM10, TSPO, TIMM9, TIMM17A, TOMM7, TIMM13, and TIMM8B) involved in proteins import into mitochondrion (mean FC of 1.34) and of several mitochondrial ribosomal proteins (MRPL13, MRPL20, MRPL21, MRPL33, MRPL51, MRPL52, MRPS25, MRPS30, MRPS33, MRPS36, RPL10A, RPL13, RPL15, RPL22, RPL22L1, RPL26, RPL31, RPL32, RPL39L, RPS10, RPS25, RPS26, RPS26P11, RPS29, RPS5, and RPS7) with a mean FC of 1.5.
All together these lines of evidence seem to suggest an increased mitochondrial activity that might be linked to the observation of the pathologic phenotype. Anyways at this stage of the study, it is not possible to determine whether or not there is an increase in ATP levels. It is possible to speculate that increased genes related to mitochondrial subunits could be a consequence of increased cells request of energy (ATP). This hypothesis is in line with recent study where the authors have shown decreased levels of ATP in brain mouse RTT [34].

Recent discussions regarding a possible connection between RTT and mitochondrial dysfunction have generated significant interest. The basis for these discussions is related in part to the common features of RTT on the one hand and disorders of mitochondrial function on the other. Of interest is the fact that a patient with symptoms normally associated with mitochondrial disorders harbored mutations in the $M e C P 2$ gene [35]. This overlap between symptoms of RTT and mitochondrial disorders recalls early reports of structural abnormalities [36, 37] and defects in the electron transport chain $[37,38]$ in mitochondria from skin and muscle biopsies of RTT patients. Moreover, about half of RTT patients were reported to have elevated levels of circulatory lactic or pyruvic acid, which might be caused by defects in the efficiency of the respiratory chain and urea cycle complexes, both of which are mitochondrial [39-41]. Several disorders related to the brain are a consequence of mitochondrial alteration with the resultant increase of OS and in certain cases the cell apoptosis. As RTT is not a neurodegenerative disorder [42], any contribution of mitochondrial dysfunction to RTT symptoms may take the form of chronic mitochondrial underperformance, rather than catastrophic failure leading to neuronal death.

To date, no systematic study of mitochondrial function in individuals with RTT has presented whether these findings represent a primary or secondary effect; that is, are they involved directly in the clinical features of RTT or do they reflect effects of these clinical features on mitochondrial function? Prior to identification of mutations in MeCP2 in 1999, several reports appeared to be related to mitochondrial structure and function [36-54]. However, since 2001, publications on a possible role of mitochondria in the pathogenesis of RTT have been very few $[36,54]$. In a recent work, investigators in Australia reported gene expression results from postmortem brain tissue of individuals with RTT and normal controls [55]. One gene related to a mitochondrial enzyme, cytochrome c oxidase subunit 1 , had reduced expression in RTT tissue raising the possibility that loss of MeCP2 function could be responsible. However, whether this is a primary or secondary finding remains to be established and provides an important target for further investigation.

In summary, while mitochondrial abnormalities related to structure and functions have been reported, sufficient information is lacking as to the precise role of such abnormalities in RTT. As mentioned, alteration of mitochondrial functions is often correlated with OS and, in particular, the mitochondrial sites that are often invoked as the most important mitochondrial superoxide producers are in respiratory complexes I and III $[56,57]$ and this can explain the increased OS levels found in RTT patients. 

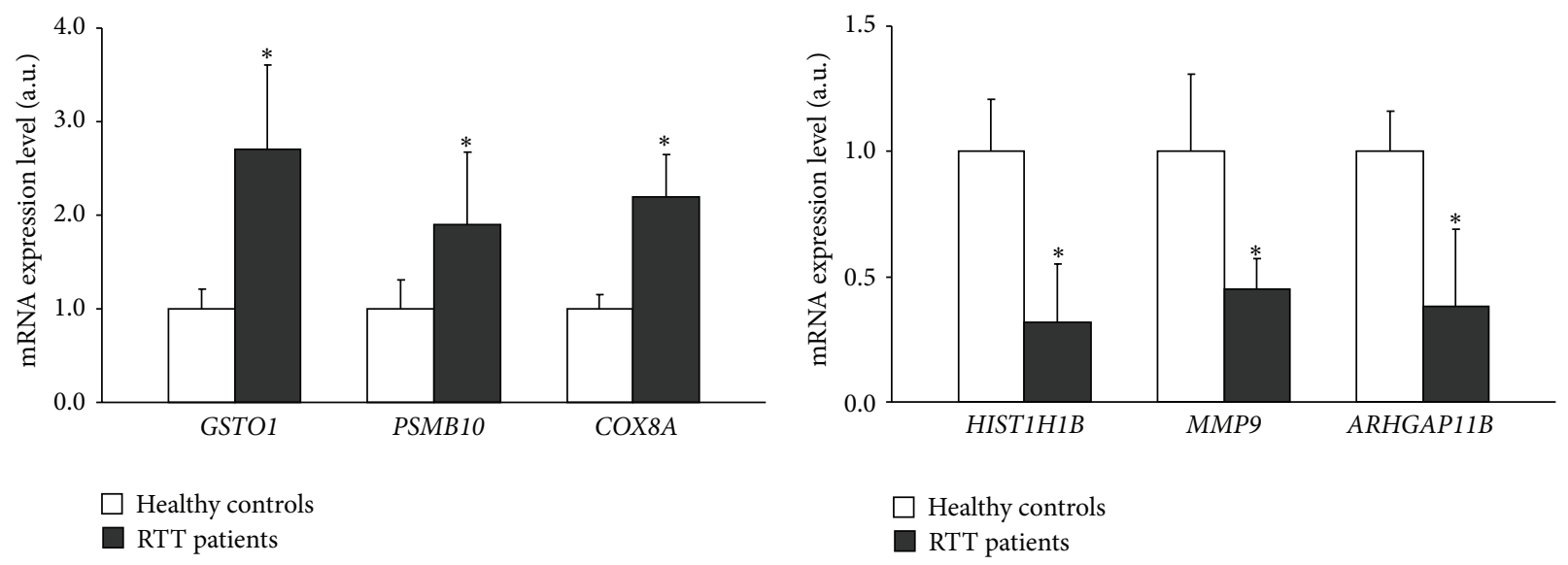

FIGURE 2: Validation of relative gene expression levels for selected genes using RT-qPCRin PBMC from 12 RTT patients and 7 controls. Results are the means \pm SEM of three independent experiments, each analysed in triplicate. ${ }^{*} P$ value $<0.001$ versus control (one-way ANOVA followed by Bonferroni's post-test).

3.3. Oxidative Stress Related Genes in RTT Patients. The presence of a redox unbalance in RTT is confirmed by the upregulations of several genes involved in redox homeostasis such as superoxide dismutase 1 , catalase, and peroxiredoxin 1 (SOD1, CAT, and PRDX1) with a 1.6, 1.14, and $1.12 \mathrm{FC}$, respectively. Moreover, glutathione S-transferase omega 1, microsomal glutathione S-transferase 2, and microsomal glutathione S-transferase 3 (GSTO1, MGST2, and MGST3) are also overexpressed in RTT with a FC $=2.1$. For instance, $S O D 1$ upregulation could be a consequence of increased superoxide production by aberrant activation of complex I and III and the dismutation of superoxide in $\mathrm{H}_{2} \mathrm{O}_{2}$ can explain the increased expression of CAT and PRDX1. It is likely to believe that the compensatory antioxidant system is not quite sufficient to quench ROS production and this could explain the high OS level present in RTT $[22,23]$. For this reason the induction of glutathione S-transferase omega-1 (GSTO1) is not surprising. This enzyme is involved in the detoxification mechanisms via conjugation of reduced glutathione (GSH) to oxidativelly modified proteins (carbonyls and 4-HNE PAs). In fact, the GST genes are upregulated in response to OS. In addition, our results showed the upregulation of MGST2 and MGST3 which are the microsomal glutathione S-transferases; this data correlates very well with our previous findings where RTT patients showed an increased level of 4-HNE PAs, as MGST2 is able to also conjugate 4-HNE with GSH [58]. We also observed an increased expression of mRNA for alcohol dehydrogenase $5(A D H 5)$, aldo-keto reductase family 1, member A1 (AKR1A1) and aldehyde dehydrogenase 1 family, member A1 (ALDH1A1), all enzymes involved in lipid peroxidation products detoxification [59].

3.4. Ubiquitin-Proteasome Related Genes in RTT Patients. Our results evidenced also the upregulation of genes related to protein degradation and ubiquitination. In fact, RTT PBMC microarray data revealed increased expression levels of genes associated with protein turnover, such as genes encoding proteasome subunits (PSMA2, PSMA3,
PSMA5, PSMA7, PSMB1, PSMB10, PSMC5, PSMC6, PSMD6, and $P S M D 9)$; furthermore, proteasome maturation protein $(P O M P)$, involved in proteasome assembly, and genes regulating the activity of the ubiquity ligases (RBX1, UFC1, $C C N B 1 I P 1$, and $D A X X$ ) are also up regulated (Table 2), suggesting an increase in cell and protein degradation processes. This could also be a consequence of oxidized proteins and the presence of 4-HNE PAs. This evidence is supported by the observed upregulation of the ubiquitin-conjugating enzyme E2E3 ( $U B E 2 E 3, F C=1.19)$ that accepts ubiquitin from the E1 complex and catalyzes its covalent attachment to other proteins. However, this is in contrast with some lines of evidence that link RTT to the downregulation of ubiquitin conjugating enzymes $(U B E 3 A)$ by MeCP2 [60]. Overall the effect of $\mathrm{MeCP} 2$ on $U B E 3 A$ regulation is still controversial. In fact, there is even a recent work that did not find any difference in $U B E 3 A$ expression between wild type and a RTT mouse with the mutation R168X [61]. In general, the levels of protein ubiquitination, that is one of the steps to degrade modified proteins, are increased in RTT [24].

3.5. Chromatin Folding Related Genes in RTT Patients. In addition several histone related genes (HIST1H1B, HIST1H2AB, HIST1H2AI, HIST1H2AJ, HIST1H2AL, HIST1H2BB, HIST1H2BH, HIST1H2BM, HIST1H3B, HIST1H3F, HIST1H3I, HIST1H3J, HIST1H4D, HIST1H4F, and HIST1H4) were downregulated with a mean FC of -1.28 suggesting a reduced production of proteins necessary to the DNA chromatin assembly.

In general, histone modifications are very dynamic and include acetylation, methylation, isomerization, phosphorylation, and ubiquitination [62]. The combination of such modifications confers enormous variability of cellular signals to environmental stimuli. It is easy to understand that modifications such as histone methylation can display additional complexity since the degree of methylation is very variable (mono-, di-, or trimethylation) [63]. Furthermore, combinations or sequential additions of different histone marks can 


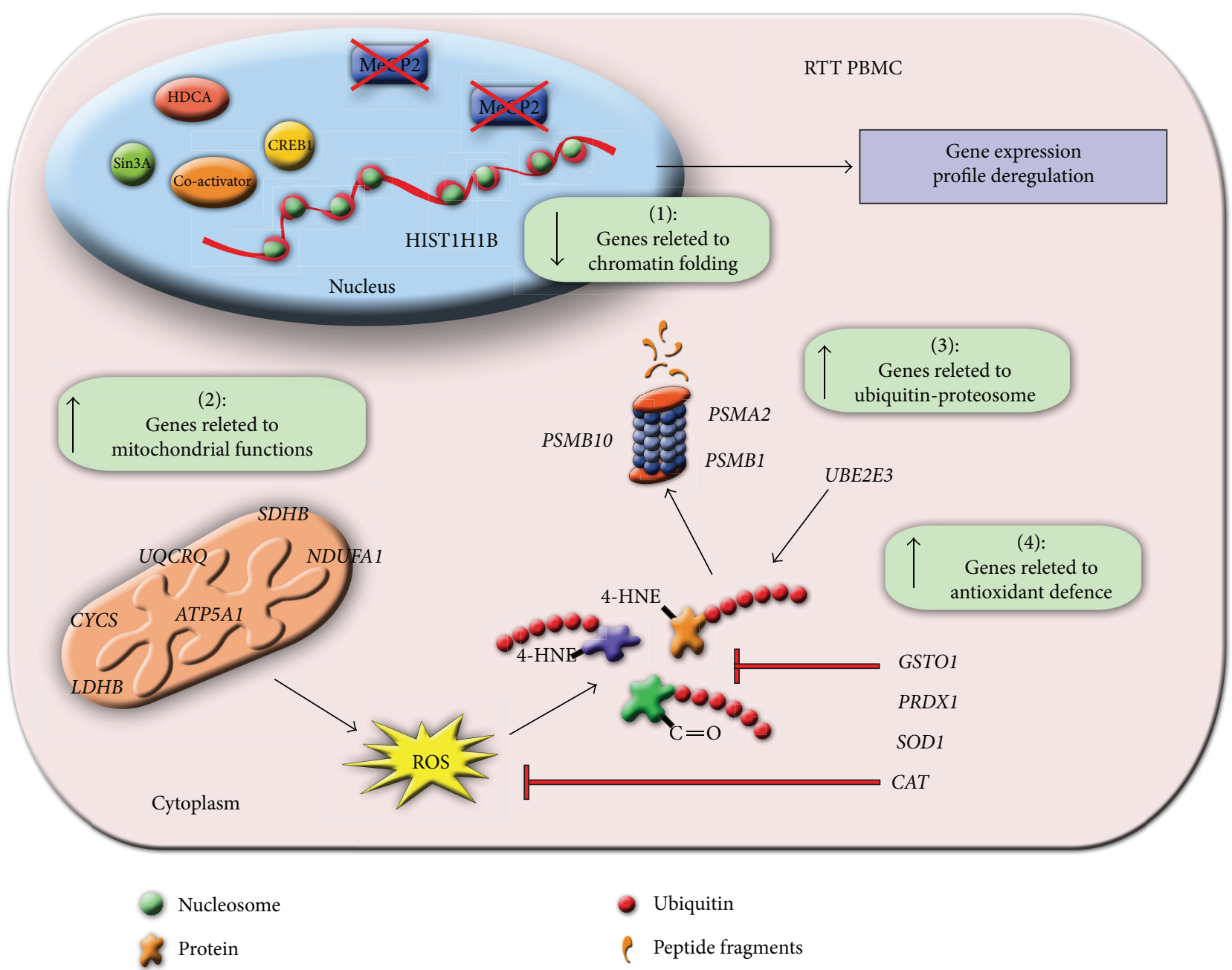

Scheme 1: Schematic summary related to the altered gene expression observed in RTT PBMC. MeCP2 in a normal situation binds to several cofactors (Sin3A, CREB1, etc.) to regulate gene transcription. Mutation of MeCP2 (crossed boxes) will affect gene expression leading to a gene profile deregulation. There are mainly 4 gene clusters significantly affected in RTT PBMC, that is, those related to chromatin folding (1), mitochondrial functions (2), ubiquitin-proteasome (3), and antioxidant defence (4) (green boxes). The overexpression of the genes involved in ATP synthesis processes (2) can be interpreted as a possible energy requirement for an increment of cellular protein degradation (3), consequent to increased mitochondrial ROS production and protein oxidation. The increased expression of the "antioxidant cellular defence" genes (4) is the possible compensatory mechanism activated by the cells to quench ROS production and protein oxidation (red arrows).

affect the chromatin organization and subsequently alter the expression of the corresponding target genes.

In our case, several genes related to histone expression were downregulated and this can dramatically affect gene expression. For instance, histone $\mathrm{H} 1$ protein binds to linker DNA between nucleosomes forming the macromolecular structure known as the chromatin fiber. Histones $\mathrm{H} 1$ are necessary for the condensation of nucleosome chains into higher-order structured fibers. Acts also as a regulator of individual gene transcription through chromatin remodeling, nucleosome spacing, and DNA methylation. We have detected a down-regulation of several $\mathrm{H} 1$ subunits ranging from 2- to 3-fold in RTT patients.

3.6. Validation of Selected PBMC mRNAs by qPCR Analyses. Next, we wanted to confirm the differential expression observed for selected mRNAs, on an individual basis, by RT-qPCR. Six genes were selected based on their different patterns of expression (3 up- and 3 downregulated). Assessment of their mRNA expression levels by RT-qPCR accurately reflected those obtained by microarray profiling (Figure 2), thereby confirming the validity of our microarray results. The levels of three mRNAs encoding for glutathione S-transferase omega 1 (GSTO1), proteasome (prosome, macropain) subunit, beta type-10 (PSMB10), and cytochrome c oxidase subunit VIIIA (COX8A) were upregulated in RTT patients by 2.5-, 2- and 2.2-fold, respectively (Figure 2), very similarly to the levels measured by gene array. In contrast, histone cluster 1, H1b (HIST1H1B), matrix metallopeptidase 9 (MMP9), and Rho GTPase activating protein 11B (ARHGAP11B) were downregulated by $\sim 50 \%$ in RTT patients, as compared to healthy subjects (Figure 2) and also in this case similar expression was detected by gene array analysis. 
3.7. Conclusion. Our microarray data reveal an altered gene expression profile in RTT lymphomonocytes with the upregulation of genes related to mitochondrial biology and ubiquitin-proteasome proteolytic pathway. In particular, the overexpression of the genes involved in ATP synthesis processes means the tendency of cells to show an altered energy requirement, perhaps to cope with the increased activities of protein degradation. On the other hand, it should be noted that mitochondrion plays essential roles in mediating the production of ROS and these in turn cause damage to proteins, as well as lipids and nucleic acids. To remove damaged molecules, in a kind of vicious circle, increased cellular proteolytic activity requires an extra mitochondrial ATP production with a further ROS generation. This picture is consistent with our previous reports [24], indicating the alteration of redox status in RTT patients, coupled with the increased ubiquitination and degradation of oxidatively modified proteins (Scheme 1).

In conclusion, these findings on transcriptional profiling in RTT patients reveal new molecular mechanisms underlying RTT phenotype, suggesting that mitochondrialATP-proteosome are likely to have direct actions on redox balance in RTT syndrome. Furthermore, it confirmed a possible indirect role of OS in pathogenesis and progression of disorder. Thus, RTT should be considered as possible mitochondriopathy.

\section{Acknowledgments}

The authors thank "Fondazione Monte Dei Paschi", Associazione Italiana Rett (AIRETT) and Tuscany Region (Bando Salute 2009, "Antioxidants ( $\omega$-3 polyunsaturated fatty acids, Lipoic Acid) Supplementation in Rett Syndrome: a novel approach to therapy"), for partial support.

\section{References}

[1] A. Rett, "On a unusual brain atrophy syndrome in hyperammonemia in childhood," Wiener Medizinische Wochenschrift, vol. 116, no. 37, pp. 723-726, 1966.

[2] B. Hagberg, "Rett's syndrome: prevalence and impact on progressive severe mental retardation in girls," Acta Paediatrica Scandinavica, vol. 74, no. 3, pp. 405-408, 1985.

[3] C. L. Laurvick, N. de Klerk, C. Bower et al., "Rett syndrome in Australia: a review of the epidemiology," Journal of Pediatrics, vol. 148, no. 3, pp. 347-352, 2006.

[4] J. L. Neul, W. E. Kaufmann, D. G. Glaze et al., "Rett syndrome: revised diagnostic criteria and nomenclature," Annals of Neurology, vol. 68, no. 6, pp. 944-950, 2010.

[5] J. L. Neul, "The relationship of Rett syndrome and MECP2 disorders to autism," Dialogues in Clinical Neuroscience, vol. 14, no. 3, pp. 253-262, 2012.

[6] A. Bebbington, A. Anderson, D. Ravine et al., "Investigating genotype-phenotype relationships in Rett syndrome using an international data set," Neurology, vol. 70, no. 11, pp. 868-875, 2008.

[7] J. L. Neul, P. Fang, J. Barrish et al., "Specific mutations in Methyl-CpG-Binding Protein 2 confer different severity in Rett syndrome," Neurology, vol. 70, no. 16, pp. 1313-1321, 2008.
[8] R. E. Amir, I. B. Van Den Veyver, M. Wan, C. Q. Tran, U. Francke, and H. Y. Zoghbi, "Rett syndrome is caused by mutations in X-linked MECP2, encoding methyl-CpG-binding protein 2," Nature Genetics, vol. 23, no. 2, pp. 185-188, 1999.

[9] M. Chahrour and H. Y. Zoghbi, "The story of Rett syndrome: from clinic to neurobiology," Neuron, vol. 56, no. 3, pp. 422-437, 2007.

[10] N. L. Adkins and P. T. Georgel, "MeCP2: structure and function," Biochemistry and Cell Biology, vol. 89, no. 1, pp. 1-11, 2011.

[11] J. Guy, H. Cheval, J. Selfridge, and A. Bird, "The role of MeCP2 in the brain," Annual Review of Cell and Developmental Biology, vol. 27, pp. 631-652, 2011.

[12] C. Colantuoni, O.-H. Jeon, K. Hyder et al., "Gene expression profiling in postmortem Rett Syndrome brain: differential gene expression and patient classification," Neurobiology of Disease, vol. 8, no. 5, pp. 847-865, 2001.

[13] J. Nectoux, Y. Fichou, H. Rosas-Vargas et al., "Cell cloningbased transcriptome analysis in Rett patients: relevance to the pathogenesis of Rett syndrome of new human MeCP2 target genes," Journal of Cellular and Molecular Medicine, vol. 14, no. 7, pp. 1962-1974, 2010.

[14] J. Traynor, P. Agarwal, L. Lazzeroni, and U. Francke, "Gene expression patterns vary in clonal cell cultures from Rett syndrome females with eight different MECP2 mutations," BMC Medical Genetics, vol. 3, article 12, 2002.

[15] E. Ballestar, S. Ropero, M. Alaminos et al., "The impact of MECP2 mutations in the expression patterns of Rett syndrome patients," Human Genetics, vol. 116, no. 1-2, pp. 91-104, 2005.

[16] I. J. Delgado, D. S. Kim, K. N. Thatcher, J. M. LaSalle, and I. B. Van den Veyver, "Expression profiling of clonal lymphocyte cell cultures from Rett syndrome patients," BMC Medical Genetics, vol. 7, article 61, 2006.

[17] S. Yakabe, H. Soejima, H. Yatsuki et al., "MeCP2 knockdown reveals DNA methylation-independent gene repression of target genes in living cells and a bias in the cellular location of target gene products," Genes and Genetic Systems, vol. 83, no. 2, pp. 199-208, 2008.

[18] D. H. Yasui, H. Xu, K. W. Dunaway, J. M. Lasalle, L. W. Jin, and I. Maezawa, "MeCP2 modulates gene expression pathways in astrocytes," Molecular Autism, vol. 4, no. 1, p. 3, 2013.

[19] G. Dennis Jr., B. T. Sherman, D. A. Hosack et al., "DAVID: database for annotation, visualization, and integrated discovery," Genome Biology, vol. 4, no. 5, p. P3, 2003.

[20] Y. Benjamini and Y. Hochberg, "Controlling the false discovery rate: a practical and powerful approach to multiple testing," Journal of the Royal Statistical Society, vol. 57, no. 1, pp. 289-300, 1995.

[21] F. Cervellati, G. Valacchi, L. Lunghi et al., "17- $\beta$-estradiol counteracts the effects of high frequency electromagnetic fields on trophoblastic connexins and integrins," Oxidative Medicine and Cellular Longevity, vol. 2013, Article ID 280850, 11 pages, 2013.

[22] C. De Felice, L. Ciccoli, S. Leoncini et al., "Systemic oxidative stress in classic Rett syndrome," Free Radical Biology and Medicine, vol. 47, no. 4, pp. 440-448, 2009.

[23] A. Pecorelli, L. Ciccoli, C. Signorini et al., "Increased levels of 4HNE-protein plasma adducts in Rett syndrome," Clinical Biochemistry, vol. 44, no. 5-6, pp. 368-371, 2011.

[24] C. Sticozzi, G. Belmonte, and A. Pecorelli, "Scavenger receptor B1 post-translational modifications in Rett syndrome," FEBS Letters, vol. 587, no. 14, pp. 2199-2204, 2013. 
[25] L. Iommarini, M. A. Calvaruso, I. Kurelac, G. Gasparre, and A. M. Porcelli, "Complex I impairment in mitochondrial diseases and cancer: parallel roads leading to different outcomes," The International Journal of Biochemistry \& Cell Biology, vol. 45, no. 1, pp. 47-63, 2013.

[26] R. Stefanatos and A. Sanz, "Mitochondrial complex I: a central regulator of the aging process," Cell Cycle, vol. 10, no. 10, pp. 1528-1532, 2011.

[27] D. N. Hauser and T. G. Hastings, "Mitochondrial dysfunction and oxidative stress in Parkinson's disease and monogenic parkinsonism," Neurobiology of Disease, vol. 51, pp. 35-42, 2013.

[28] U. N. Das, "Autism as a disorder of deficiency of brain-derived neurotrophic factor and altered metabolism of polyunsaturated fatty acids," Nutrition, vol. 29, no. 10, pp. 1175-1185, 2013.

[29] T. Clark-Taylor and B. E. Clark-Taylor, "Is autism a disorder of fatty acid metabolism? Possible dysfunction of mitochondrial $\beta$-oxidation by long chain acyl-CoA dehydrogenase," Medical Hypotheses, vol. 62, no. 6, pp. 970-975, 2004.

[30] S. Kriaucionis, A. Paterson, J. Curtis, J. Guy, N. MacLeod, and A. Bird, "Gene expression analysis exposes mitochondrial abnormalities in a mouse model of Rett syndrome," Molecular and Cellular Biology, vol. 26, no. 13, pp. 5033-5042, 2006.

[31] C. Battisti, P. Formichi, S. A. Tripodi et al., "Lymphoblastoid cell lines of Rett syndrome patients exposed to oxidative-stressinduced apoptosis," Brain and Development, vol. 26, no. 6, pp. 384-388, 2004.

[32] M. Anvret, Z. P. Zhang, and B. Hagberg, "Rett syndrome: the bcl-2 gene-a mediator of neurotrophic mechanisms?" Neuropediatrics, vol. 25, no. 6, pp. 323-324, 1994.

[33] M. Sánchez-Aragó, L. Formentini, I. Martínez-Reyes et al., "Expression, regulation and clinical relevance of the ATPase inhibitory factor 1 in human cancers," Oncogenesis, vol. 2, article e46, 2013.

[34] V. Saywell, A. Viola, S. Confort-Gouny, Y. Le Fur, L. Villard, and P. J. Cozzone, "Brain magnetic resonance study of Mecp2 deletion effects on anatomy and metabolism," Biochemical and Biophysical Research Communications, vol. 340, no. 3, pp. 776783, 2006.

[35] H. A. Heilstedt, M. D. Shahbazian, and B. Lee, "Infantile hypotonia as a presentation of Rett syndrome," American Journal of Medical Genetics, vol. 111, no. 3, pp. 238-242, 2002.

[36] A. Ruch, T. W. Kurczynski, and M. E. Velasco, "Mitochondrial alterations in Rett syndrome," Pediatric Neurology, vol. 5, no. 5, pp. 320-323, 1989.

[37] M. T. Dotti, L. Manneschi, A. Malandrini, N. De Stefano, F. Caznerale, and A. Federico, "Mitochondrial dysfunction in Rett syndrome. An ultrastructural and biochemical study," Brain and Development, vol. 15, no. 2, pp. 103-106, 1993.

[38] S. B. Coker and A. R. Melnyk, "Rett syndrome and mitochondrial enzyme deficiencies," Journal of Child Neurology, vol. 6, no. 2, pp. 164-166, 1991.

[39] T. Matsuishi, F. Urabe, A. K. Percy et al., "Abnormal carbohydrate metabolism in cerebrospinal fluid in Rett syndrome," Journal of Child Neurology, vol. 9, no. 1, pp. 26-30, 1994.

[40] R. H. Haas, M. Light, M. Rice, and B. A. Barshop, "Oxidative metabolism in Rett syndrome-1. Clinical studies," Neuropediatrics, vol. 26, no. 2, pp. 90-94, 1995.

[41] A. A. Al-Jarallah, M. A. M. Salih, M. N. Al Nasser, F. A. Al Zamil, and J. Al Gethmi, "Rett syndrome in Saudi Arabia: report of six patients," Annals of Tropical Paediatrics, vol. 16, no. 4, pp. 347352, 1996.
[42] D. D. Armstrong, "Neuropathology of Rett syndrome," Mental Retardation and Developmental Disabilities Research Reviews, vol. 8, no. 2, pp. 72-76, 2002.

[43] O. Eeg-Olofsson, A. G. H. Al-Zuhair, A. S. Teebi, and M. M. N. Al-Essa, "Abnormal mitochondria in the Rett syndrome," Brain and Development, vol. 10, no. 4, pp. 260-262, 1988.

[44] O. Eeg-Olofsson, A. G. H. Al-Zuhair, A. S. Teebi, and M. M. N. Al-Essa, "Rett syndrome: genetic clues based on mitochondrial changes in muscle," American Journal of Medical Genetics, vol. 32, no. 1, pp. 142-144, 1989.

[45] O. Eeg-Olofsson, A. G. H. Al-Zuhair, A. S. Teebi et al., "Rett syndrome: a mitochondrial disease?" Journal of Child Neurology, vol. 5, no. 3, pp. 210-214, 1990.

[46] S. Wakai, K. Kameda, Y. Ishikawa et al., "Rett syndrome: findings suggesting axonopathy and mitochondrial abnormalities," Pediatric Neurology, vol. 6, no. 5, pp. 339-343, 1990.

[47] S.-C. Mak, C.-S. Chi, C.-H. Chen, and W.-J. Shian, "Abnormal mitochondria in Rett syndrome: one case report," Chinese Medical Journal, vol. 52, no. 2, pp. 116-119, 1993.

[48] M. E. Cornford, M. Philippart, B. Jacobs, A. B. Scheibel, and H. V. Vinters, "Neuropathology of Rett syndrome: case report with neuronal and mitochondrial abnormalities in the brain," Journal of Child Neurology, vol. 9, no. 4, pp. 424-431, 1994.

[49] S. Naidu, S. Hyman, E. L. Harris, V. Narayanan, D. Johns, and F. Castora, "Rett syndrome studies of natural history and search for a genetic marker," Neuropediatrics, vol. 26, no. 2, pp. 63-66, 1995.

[50] J. Tang, Y. Qi, X.-H. Bao, and X.-R. Wu, "Mutational analysis of mitochondrial DNA of children with Rett syndrome," Pediatric Neurology, vol. 17, no. 4, pp. 327-330, 1997.

[51] C. Ellaway and J. Christodoulou, "Rett syndrome: clinical update and review of recent genetic advances," Journal of Paediatrics and Child Health, vol. 35, no. 5, pp. 419-426, 1999.

[52] Y. Oi, X. Wu, J. Tang, and X. Bao, "Computerized ribosomal RNA secondary structure modeling of mutants found in Rett syndrome patients and their mothers," Chinese Journal of Medical Genetics, vol. 16, no. 3, pp. 153-155, 1999.

[53] J. Armstrong, M. Pineda, and E. Monrós, "Mutation analysis of $16 \mathrm{~S}$ rRNA in patients with rett syndrome," Pediatric Neurology, vol. 23, no. 1, pp. 85-87, 2000.

[54] H. Meng, H. Pan, and Y. Qi, "Role of mitochondrial lesion in pathogenesis of sporadic rett syndrome," Zhonghua yi xue za zhi, vol. 81, no. 11, pp. 662-664, 2001.

[55] J. H. Gibson, B. Slobedman, H. KN et al., "Downstream targets of methyl CpG binding protein 2 and their abnormal expression in the frontal cortex of the human Rett syndrome brain," $B M C$ Neuroscience, vol. 11, article 53, 2010.

[56] M. D. Brand, "The sites and topology of mitochondrial superoxide production," Experimental Gerontology, vol. 45, no. 7-8, pp. 466-472, 2010.

[57] S. Dröse and U. Brandt, "Molecular mechanisms of superoxide production by the mitochondrial respiratory chain," Advances in Experimental Medicine and Biology, vol. 748, pp. 145-169, 2012.

[58] S. Ahmad, D. Niegowski, A. Wetterholm, J. Z. Haeggström, R. Morgenstern, and A. Rinaldo-Matthis, "Catalytic characterization of human microsomal glutathione s-transferase 2: identification of rate-limiting steps," Biochemistry, vol. 52, no. 10, pp. 1755-1764, 2013.

[59] G. Poli, R. J. Schaur, W. G. Siems, and G. Leonarduzzi, "4-Hydroxynonenal: a membrane lipid oxidation product of 
medicinal interest," Medicinal Research Reviews, vol. 28, no. 4, pp. 569-631, 2008.

[60] K. Makedonski, L. Abuhatzira, Y. Kaufman, A. Razin, and R. Shemer, "MeCP2 deficiency in Rett syndrome causes epigenetic aberrations at the PWS/AS imprinting center that affects UBE3A expression," Human Molecular Genetics, vol. 14, no. 8, pp. 1049-1058, 2005.

[61] A. Lawson-Yuen, D. Liu, L. Han et al., "Ube3a mRNA and protein expression are not decreased in Mecp2R168X mutant mice," Brain Research, vol. 1180, no. 1, pp. 1-6, 2007.

[62] G. P. Delcuve, M. Rastegar, and J. R. Davie, "Epigenetic control," Journal of Cellular Physiology, vol. 219, no. 2, pp. 243-250, 2009.

[63] J. C. Rice and C. D. Allis, "Histone methylation versus histone acetylation: new insights into epigenetic regulation," Current Opinion in Cell Biology, vol. 13, no. 3, pp. 263-273, 2001. 


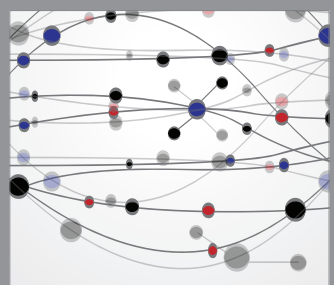

The Scientific World Journal
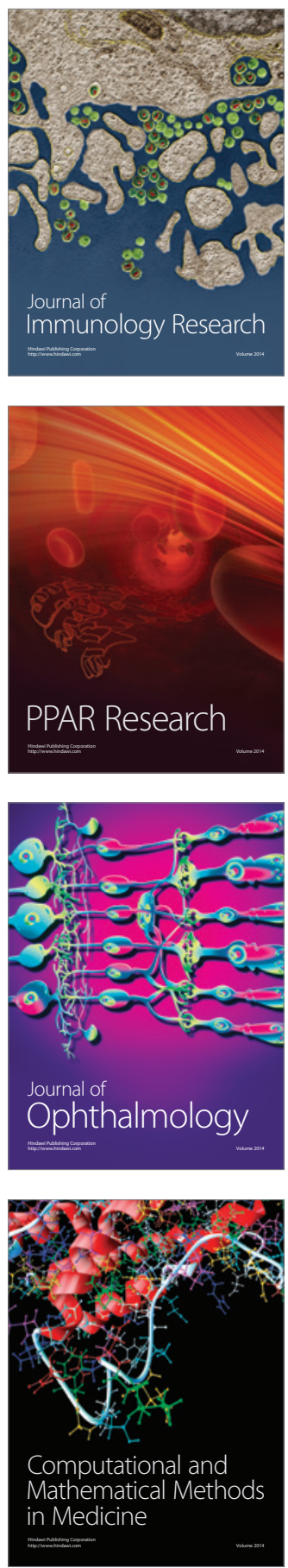

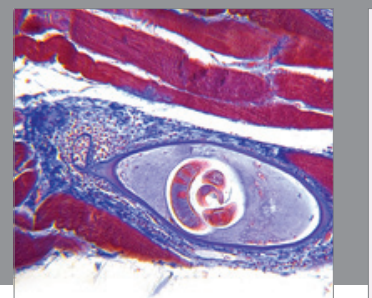

Gastroenterology

Research and Practice
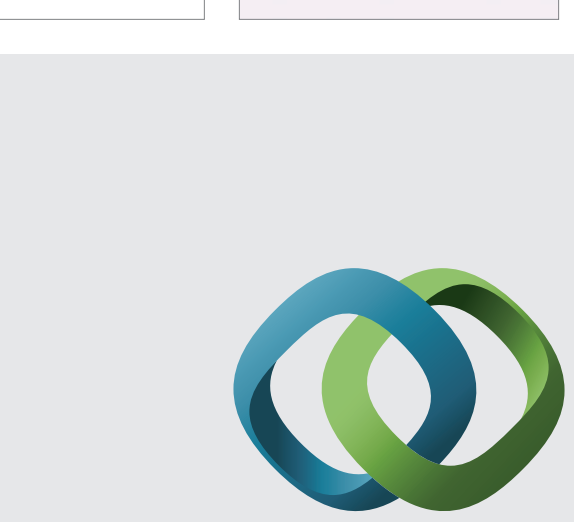

\section{Hindawi}

Submit your manuscripts at

http://www.hindawi.com
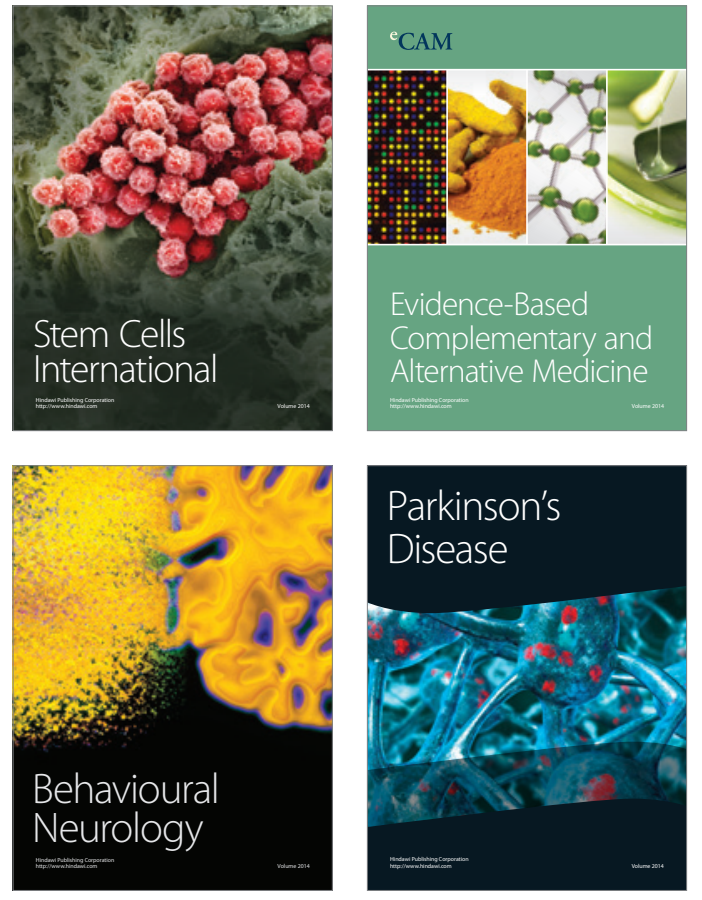
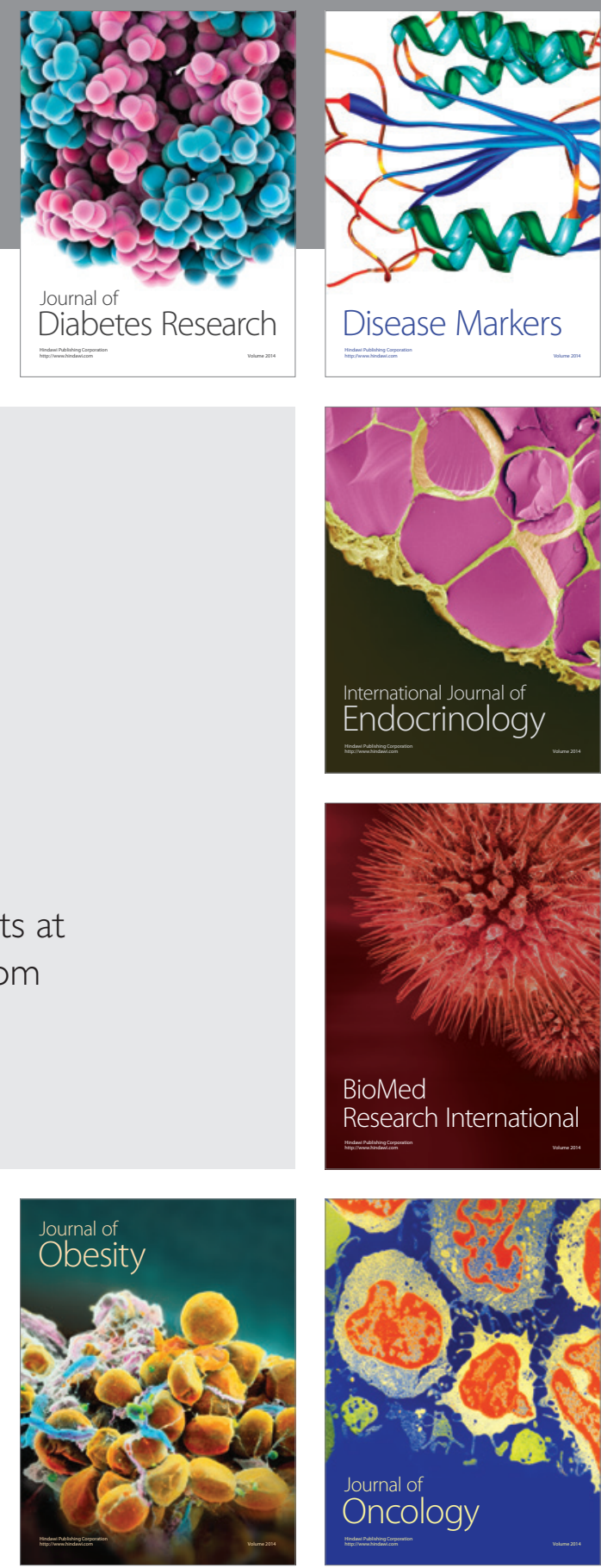

Disease Markers
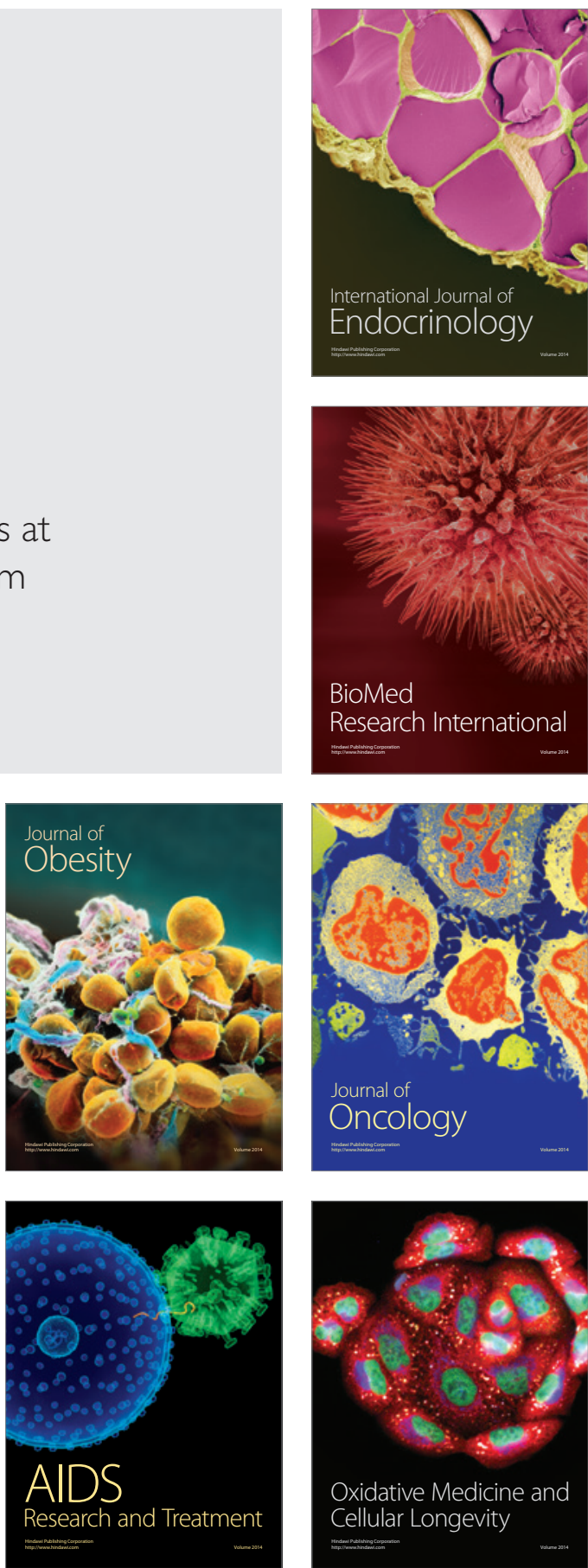